\title{
Borehole climatology: a discussion based on contributions from climate modeling
}

\author{
J. F. González-Rouco ${ }^{1}$, H. Beltrami ${ }^{2}$, E. Zorita ${ }^{3}$, and M. B. Stevens ${ }^{2}$ \\ ${ }^{1}$ Departamento Astrofísica y CC. de la Atmósfera, Universidad Complutense, Madrid, Spain \\ ${ }^{2}$ Environmental Sciences Research Centre, St. Francis Xavier Univ., Nova Scotia, Canada \\ ${ }^{3}$ GKSS Research Centre, Geesthacht, Germany
}

Received: 6 December 2007 - Published in Clim. Past Discuss.: 21 January 2008

Revised: 8 January 2009 - Accepted: 23 February 2009 - Published: 19 March 2009

\begin{abstract}
Progress in understanding climate variability through the last millennium leans on simulation and reconstruction efforts. Exercises blending both approaches present a great potential for answering questions relevant both for the simulation and reconstruction of past climate, and depend on the specific peculiarities of proxies and methods involved in climate reconstructions, as well as on the realism and limitations of model simulations. This paper explores research specifically related to paleoclimate modeling and borehole climatology as a branch of climate reconstruction that has contributed significantly to our knowledge of the low frequency climate evolution during the last five centuries.
\end{abstract}

The text flows around three main issues that group most of the interaction between model and geothermal efforts: the use of models as a validation tool for borehole climate reconstructions; comparison of geothermal information and model simulations as a means of either model validation or inference about past climate; and implications of the degree of realism on simulating subsurface climate on estimations of future climate change.

The use of multi-centennial simulations as a surrogate reality for past climate suggests that within the simplified reality of climate models, methods and assumptions in borehole reconstructions deliver a consistent picture of past climate evolution at long time scales. Comparison of model simulations and borehole profiles indicate that borehole temperatures are responding to past external forcing and that more realism in the development of the soil model components in climate models is desirable. Such an improved degree of

\section{Correspondence to:}

J. F. González-Rouco

(fidelgr@fis.ucm.es) realism is important for the simulation of subsurface climate and air-ground interaction; results indicate it could also be crucial for simulating the adequate energy balance within climate change scenario experiments.

\section{Introduction}

The purpose of this text is to illustrate and discuss advances at the interface of climate reconstruction studies and General Circulation Model simulations. The discourse specifically focuses on the climate of the last millennium and on borehole climatology applications as an example of blending of climate reconstruction and climate modeling efforts. This section furnishes the general context in which these studies are rooted and establishes the structure of the sections to come.

\subsection{Paleoclimate context}

The last decades have witnessed an important growth in research efforts and resulting knowledge regarding climate variability of the last millennium. This has been parallel to an increasing concern about the rising global and hemispherical temperatures and has offered important insights into present and future climate (Houghton, 2005; Solomon et al., 2007). This area of paleoclimate research has helped not only to place the relatively short instrumental record in a broader temporal context (Jones et al., 2001; Mitchell et al., 2001; Jones and Mann, 2004; Mann, 2007; North et al., 2006; Mann et al., 2008; Jones et al., 2009) but also to explore the mechanisms behind climate events and periods that have been the subject of longstanding scientific interest like the Late Maunder Minimum within the Little Ice Age or the

Published by Copernicus Publications on behalf of the European Geosciences Union. 
Medieval Warm period (Pfister et al., 1998; Shindell et al., 2001; Bradley et al., 2003b; Luterbacher et al., 2004; Rind et al., 2004; Zorita et al., 2004; Xoplaki et al., 2005; Goosse et al., 2006). Such insight into pre-instrumental variability has come both from climate reconstruction exercises using indirect (proxy) sources of information and from simulation of past climatic states with General Circulation Models (GCMs)

Numerical simulation has used models of varying complexity, from energy balance models (EBM, e.g. Crowley, 2000; Osborn et al., 2006) and Earth system Models of Intermediate Complexity (EMIC, e.g. Goosse et al., 2005; Bauer and Claussen, 2006) to comprehensive atmosphere ocean GCMs (AOGCM, e.g. Zorita et al., 2004; Stendel et al., 2006; Tett et al., 2007; Ammann et al., 2007).

Efforts to simulate the last millennium with high temporal and spatial resolution have been limited by the extensive computer requirements. Nevertheless, the impressive evolution of computing power in the last several years has made it possible to accomplish multi-centennial and even millennial timescale simulations with comprehensive AOGCMs. Since these models are the ones that future climate change projections rely on most heavily, evaluation of their performance in replicating aspects of climatic states different from the present is very important (Cane et al., 2006; Kageyama et al., 2006). Therefore comparison of centennial to millennial simulations and reconstructions of the late Holocene climate offer the unique possibility of validating model simulations at long timescales before the onset of the industrial era and the beginning of heavy injection of greenhouse gases into the atmosphere. In addition, these simulations offer several other research directions of relevance for the understanding of past climate and future anthropogenic climate change such as: analysis of the response to natural and anthropogenic external forcing and mechanisms involved (e.g. Cubasch et al., 1997; Haigh, 1999; Rind et al., 2004; Zorita et al., 2005; Goosse et al., 2006; Tett et al., 2007; Ammann et al., 2007); comparison of model simulations and climate reconstructions to detect the signal of the various external forcing factors through the last millennium (Crowley, 2000; Bauer et al., 2003; Hegerl et al., 2003, 2007a) or to constrain estimates of climate sensitivity (Hegerl et al., 2006); use of model simulations as a surrogate reality in which pseudo proxies are built through the transformation of simulations at the grid-point scale in order to test methods and assumptions relevant in proxy-based climate reconstructions (Mann and Rutherford, 2002; Zorita et al., 2003; von Storch et al., 2004, 2006; Mann et al., 2005, 2007b, 2008; Graham et al., 2007; Küttel et al., 2007; Moberg et al., 2008).

Climate reconstructions allow the history of climate parameters to be extended into the past before the advent of widespread instrumental records. Reconstructions are built from a variety of proxy indicators that include historical documentary records, tree-ring variables, ice cores, corals, varved lake and marine sediments, speleothems, molusc shells, etc. All these records can provide information at different temporal resolutions and with varying degrees of sensitivity to several climate parameters with an overall emphasis on temperature and precipitation (Jones et al., 1998, 2001; Bradley et al., 2003b; Jones and Mann, 2004; Jones et al., 2009). Climate reconstruction efforts have targeted a wide range of spatial scales: from the local and regional (e.g. Cook, 1995; Overpeck et al., 1997; Luterbacher et al., 2004, 2007; Guiot et al., 2005; Xoplaki et al., 2005; Büntgen et al., 2006; Meier et al., 2007) to hemispherical and global scales (e.g. Briffa et al., 1998; Mann et al., 1998, 1999; Esper et al., 2002; Moberg et al., 2005; Rutherford et al., 2005; Hegerl et al., 2007a). Though most efforts have been devoted to the reconstruction of past temperature variability, a great deal of research has also concentrated on reconstructing hydrological and atmospheric circulation patterns and indices (e.g. Villalba et al., 1998; Diaz et al., 2001; Cook et al., 2002; Luterbacher et al., 2002a,b; Pauling et al., 2006).

Hemispheric scale temperature reconstructions show general consistency in depicting broad climate periods through the last millennium (Jansen et al., 2007) like the Medieval Warm Period (MWP, centered around year 1000) or the Little Ice age (ca. 1300 to 1850). Additionally hemispheric temperatures also decreased during events of shorter duration like the Late Maunder Minimum (LMM, late 17th century), the Spörer (SM, ca. 1450) or the Dalton Minimum (DM, ca. 1800) that are likely related to minima in solar activity. Nevertheless, quantitative agreement has been so far elusive and thus a matter of considerable debate in the last few years (e.g. von Storch et al., 2004, 2006; Mann et al., 2005; Bürger and Cubasch, 2005; Bürger et al., 2006; Moberg et al., 2005; McIntyre and McKitrick, 2005; Wahl et al., 2006; Zorita et al., 2007; Mann et al., 2007a,b, 2008; Smerdon and Kaplan, 2007; Wahl and Ammann, 2007; Ammann and Wahl, 2007; Lee et al., 2008)

\subsection{Borehole climatology}

Within the context of millennial climate reconstructions, borehole temperature profiles (BTPs) have been one source of information that has significantly contributed to our understanding of centennial temperature changes (e.g. see Pollack and Huang, 2000; Demezhko, 2001; Bodri and Cermak, 2007). Climate reconstruction based on BTPs leans on the assumption that surface air temperature (SAT) changes are coupled to ground surface temperature (GST) changes and propagate to the subsurface by thermal conduction merging with the background geothermal field. The downward propagation of the climate disturbance is a function of the small thermal diffusivity of the rock (ca. $10^{-6} \mathrm{~m}^{2} \mathrm{~s}^{-1}$ ) so that the first few hundred meters below the surface store the integrated thermal signature of the last millennium. Due to the nature of heat conduction (Carslaw and Jaeger, 1959) the amplitude of surface disturbances is exponentially attenuated and their phase shifted with depth as a function of their time 
scales. Thus, heat conduction effectively operates as a low pass filter such that low-frequency waves propagate deeper than higher frequency components. This feature considerably limits borehole reconstructions to recover higher frequency (seasonal to multi-decadal) information.

Borehole climatology has developed considerably since the days when the climate signal in the subsurface was thought of as unwanted noise (Lane, 1923); presently, analyses of BTPs can be used to derive robust reconstructions of low frequency SAT changes. Since the first attempts to recover an air temperature signal (Cermak, 1971; Lachenbruch and Marshall, 1986) boreholes have offered a meaningful complementary view of temperature changes during the last few centuries. Studies have targeted various spatial scales, from local and regional (e.g. Clauser and Mareschal, 1995; Gosnold et al., 1997; Šafanda et al., 1997, 2007; Rajver et al., 1998; Harris and Gosnold, 1999; Majorowicz et al., 1999; Beltrami, 2000; Beltrami et al., 2005; Rimi, 2000; Correia and Šafanda, 2001; Gosselin and Mareschal, 2003; Goto et al., 2005; Pasquale et al., 2005; Hamza et al., 2007), to large scales (e.g. Pollack and Huang, 2000; Golovanova et al., 2001; Roy et al., 2002; Beltrami et al., 2003; Pollack et al., 2006) as well as hemispheric and global scales (e.g. Pollack et al., 1998; Huang et al., 2000; Harris and Chapman, 2001; Beltrami, 2002b; Beltrami and Bourlon, 2004; Pollack and Smerdon, 2004).

Mathematically, the recovery of the GST history can be described as determining the time dependent surface temperature boundary condition that has given rise to an observed BTP. Several methodologies have been developed for this purpose (Shen and Beck, 1991; Mareschal and Beltrami, 1992; Wang, 1992; Beltrami et al., 1997; Cooper and Jones, 1998; Rath and Mottaghy, 2007; Hopcroft et al., 2007) and some studies have devoted efforts to the comparison of different approaches usually leading to the conclusion that they provide compatible results in the absence of severe local noisy conditions (Beck et al., 1992; Shen et al., 1992, 1996). Noise in BTPs is one of the non climatological perturbing factors that can obscure the interpretation of a climate signal and several alternatives have also been developed in order to diminish this problem by placing constraints to reduce the high frequency variability of temperature with depth (Shen and Beck, 1991; Mareschal and Beltrami, 1992).

Contrary to other climate reconstruction procedures, temperature inversions obtained from borehole data are not calibrated against the instrumental record, thereby providing an independent measurement of past temperature. This approach has offered a rather singular view of the amplitude of global and hemispheric warming during the last five centuries (Huang et al., 2000; Beltrami, 2002a; Pollack and Smerdon, 2004), although recent proxy reconstructions that have sought to preserve low-frequency variance are consistent with borehole estimates (Esper et al., 2002; Moberg et al., 2005; Hegerl et al., 2007a). Nevertheless, the different magnitude of SAT changes inferred from borehole inversions and those based on other proxy reconstructions (Briffa and Osborn, 2002; Hegerl et al., 2007b) has fostered recent discussion and examination of uncertainties in the borehole approach to climate reconstruction (Mann et al., 2003; Mann and Schmidt, 2003; González-Rouco et al., 2003a, 2006; Chapman et al., 2004; Schmidt and Mann, 2004; Pollack and Smerdon, 2004).

In addition to the recovery of the past temperature evolution BTPs have also been used to evaluate the role of heat storage in the lithospheric crust within the global energy balance (Levitus et al., 2001; Pielke, 2003; Levitus et al., 2005; Hansen et al., 2005) by calculating the amount of energy stored in the ground due to GST warming (Beltrami, 2001b; Beltrami et al., 2002, 2006a). This information can be thought of as a byproduct of the temperature reconstruction analysis and, as such, it can be considered potentially subjected to the same advantages and shortcomings.

The geothermal approach, as any other method of inferring past climate, is not free from unknowns and limitations such as (see Pollack and Huang, 2000; Majorowicz et al., 2004; Bodri and Cermak, 2007): a progressive inability with depth to resolve past climate variations due to the smearing nature of heat conduction; site specific non climatic factors contributing to noise in BTPs (e.g., interaction of topography and hydrology, fluid flow and horizontal advection); long term variability in surface climate parameters which potentially disturb the SAT-GST relationship (e.g., freezing, vegetation, snow cover and evaporation changes); inhomogeneous distribution of properties related to sampling such as scarce and/or irregular spatial distribution of boreholes at regional and larger scales, spatial variation in logging dates and depth of profiles, vertical resolution, uncertainties/errors in measurements, etc. These methodological and experimental problems have been addressed in a variety of studies, the balance of which suggest that such shortcomings can be addressed and that ultimately borehole profiles, if treated appropriately, can deliver reliable information about low frequency climate evolution (e.g. Blackwell et al., 1980; Clow, 1992; Fernández and Cabal, 1992; Kukkonen and Clauser, 1994; Shen et al., 1995; Pollack et al., 1996; Kohl, 1998, 1999; Šafanda, 1999; Serban et al., 2001; Bense and Kooi, 2004; Pollack and Smerdon, 2004; Nitoiu and Beltrami, 2005; Hartmann and Rath, 2005; Ferguson et al., 2006; Bense and Beltrami, 2007; Chouinard and Mareschal, 2007; Verdoya et al., 2007).

During the last few years climate model simulation studies have targeted questions related to borehole climatology from a variety of perspectives. As in the case of other reconstruction methodologies some studies have addressed aspects of the borehole method using model simulations as a surrogate reality in which the coupling between SAT and GST at long time scales can be addressed as well as some of the uncertainties mentioned above (e.g. Mann and Schmidt, 2003; González-Rouco et al., 2003b). 
Other studies have paid attention to comparison of model simulations and borehole reconstructions or relevant thermophysical subsurface properties, serving both the purpose of model validation and also the understanding of mechanisms contributing to climate variability (e.g. Beltrami et al., 2006b; Stevens et al., 2008).

Further questions involve the expected change of subsurface properties in climate change scenarios and also whether climate models address the physics of the subsurface to account for such processes in a realistic way (e.g. Stevens et al., 2007).

The purpose of this paper is to provide an integrating discussion that incorporates research within the field of borehole climatology and GCM applications oriented towards the simulation of soil thermodynamics, model-observation comparison or methodological evaluation of the borehole reconstruction approach. These research efforts integrating experimental and model work will be illustrated by providing in each section a brief background on the basis of which a discussion will be furnished. For some specific examples we will complement the ideas discussed in the text using data from the ECHO-G GCM simulations as well as standard geothermal models.

Section 2 presents the GCM simulations and geothermal models used herein. Section 3 provides a perspective of past discussion and work concerning the validation of some hypotheses and methodological issues of the borehole approach to climate reconstruction. Section 4 focuses on the realism of GCMs in reproducing the behavior of the geothermal observations and the subsurface thermal regime. Finally, Sect. 5 presents a brief discussion on the implications of the realism of GCMs in simulating subsurface geothermics within the context of climate change simulations.

\section{Models and methods}

GCM simulations and geothermal models have been used with the purpose of illustrating some of the discussions presented herein. A brief description for them is provided in the following subsections.

\subsection{GCM simulations}

Model data were obtained from climate simulations produced with the ECHO-G atmosphere-ocean General Circulation Model (GCM). ECHO-G (Legutke and Voss, 1999) consists of the atmospheric and ocean GCM components ECHAM4 and HOPE-G, respectively. ECHAM4 (Roeckner et al., 1996) is used with a T30 horizontal resolution (ca. $3.75^{\circ}$ ) and 19 vertical levels. HOPE-G (Wolff et al., 1997) is used with a T42 (ca. $2.8^{\circ}$ ) horizontal resolution which increases towards the Equator where it reaches a minimum meridional grid point separation of $0.5^{\circ}$ for an im- proved representation of equatorial and tropical ocean currents. Vertical discretization for the ocean incorporates 20 levels.

In order to avoid climate drift, heat and freshwater flux adjustments had to be applied to the ocean. These fluxes were diagnosed in a coupled spin-up integration with restoring terms that drive the sea-surface-temperature and sea-surface salinity to their climatological observed values. These flux adjustments are constant in time through the integration and their global contribution is zero.

The surface scheme comprises a soil model, hydrology, snow cover physics and vegetation effects on surface evapotranspiration among others. The soil model, an extension of Warrilow et al. (1986), is a five layer finite-difference approximation of the diffusion equation which operates on the T 30 land-sea-mask grid of ECHAM4. Ground temperatures are simulated at five levels with depths at $0.06 \mathrm{~m}, 0.32 \mathrm{~m}$, $1.23 \mathrm{~m}, 4.13 \mathrm{~m}$ and $9.83 \mathrm{~m}$. A zero heat flux is prescribed at the lowest layer in order to ensure that no artificial heat sources and sinks affect the energy balance. This issue will be further discussed in Sect. 5

This work makes use of three integrations with the ECHOG GCM: a 1000 year long control simulation (CTRL) in which external forcings were fixed to the values of present climate and two forced simulations (FOR1 and FOR2) covering the period 1000 to 1990 produced by driving the model with estimates of external forcing factors: atmospheric greenhouse gas concentrations, solar irradiance and an estimate of the radiative effects of stratospheric volcanic aerosols. Sulphate aerosols or vegetation changes are not included in these simulations and some relative cooling effect from these forcing factors (Bauer et al., 2003; Osborn et al., 2006) should be expected to dampen the simulated warming trends in the 20th century.

The two forced simulations started from different initial conditions and were driven by identical external forcing values. FOR1 (FOR2) was started from initial conditions in a relatively warm (cold) state and taken in 100 years to the historical forcing of year $1000 \mathrm{AD}$. From that point onward the external forcing was changed according to estimates described below. Figure 1a shows the estimation of external forcings used to drive the model. The atmospheric concentrations of $\mathrm{CO}_{2}$ and $\mathrm{CH}_{4}$ were obtained from analysis of air bubbles in Antarctica ice cores (Etheridge et al., 1996, 1998). Concentrations of $\mathrm{N}_{2} \mathrm{O}$ were used as in previous scenario experiments with this model (Roeckner et al., 1999): a constant value of $276.7 \mathrm{ppb}$ before 1860 and the historical evolution from 1860 to 1990 which was adjusted from Battle et al. (1996).

The past variations of solar irradiance were derived from observations of sun spots and concentrations of the ${ }^{10} \mathrm{Be}$ cosmogenic isotope (Lean et al., 1995; Crowley, 2000). The effect of volcanic aerosols is incorporated as global effective variations of the annual values of the solar constant obtained from short wave radiative forcing changes (Crowley, 2000). 
All these forcings are subject to uncertainties, the largest of them being perhaps those related to the natural factors (volcanic and solar irradiance). $\mathrm{CH}_{4}$ presents relatively small uncertainties (Etheridge et al., 1998); estimations of $\mathrm{CO}_{2}$ changes are found to be robust in new measurements (Etheridge et al., 1996; Siegenthaler et al., 2005), and $\mathrm{N}_{2} \mathrm{O}$ shows perhaps larger uncertainties though their impact is smaller. Volcanic forcing estimates show a high degree of variability according to different authors (e.g., Crowley, 2000; Robertson et al., 2001; Ammann et al., 2003; Gao et al., 2008); in addition to that, taking into account the impacts of volcanic events as an equivalent change in solar constant does not allow for the specification of the place and moment of eruptions and the possible spatial heterogeneity in the spread of emitted aerosols.

Solar irradiance changes can play a major role in forcing decadal to centennial variability through the last millennium (Crowley, 2000; Ammann et al., 2007) and the amplitude of its variations is under discussion (Bard et al., 2000; Lean et al., 2002; Foukal et al., 2004; Solanki and Krivova, 2004). The ${ }^{10} \mathrm{Be}$ Lean et al. (1995) rescaled estimations used in this case display changes of total solar irradiance between the LMM and present values of $0.30 \%$, which are equivalent to those in other exercises (Bauer et al., 2003; Mann et al., 2005). Recent comparisons of NCAR CSM simulations using several past solar variability scenarios (Ammann et al., 2007) with NH temperature reconstructions are in good agreement for the scenario of lowest past solar variability (LMM to present changes of $0.1 \%$ ) with temperature reconstructions showing a lower range of variability through the last millennium (e.g. Mann and Jones, 2003). In turn, the intermediate solar variability scenario is comparable to the one used in this study (irradiance changes since LMM to present of $0.25 \%$ ), and agrees better with reconstructions showing larger changes in centennial temperature (e.g. Huang and Pollack, 1998; Moberg et al., 2005).

Further description and discussion of uncertainties related to external forcing can be found in Gouirand et al. (2007a) and Zorita et al. (2007).

Figure $1 \mathrm{~b}$ shows the $\mathrm{NH}$ land temperature evolution in the three simulations. CTRL presents fairly stable values over the 1000 year period and FOR1 and FOR2 show a clear response to solar and volcanic forcing in the preindustrial era and the warming during the last centuries following the increase in solar irradiance and greenhouse gases. FOR 1 presents comparatively warmer values in the first centuries of the simulation. Goosse et al. (2005) and Osborn et al. (2006) suggest that FOR 1 is unusually warm in comparison with other model simulations, a feature that can be related to warm initial conditions and the relatively short spin down to the forcing conditions of year 1000 .

Although the possibility of some initial imbalance can not be ruled out in FOR 2, the level of medieval warming simulated in FOR2 can be supported with results from another more recent simulation with an state of the art GCM

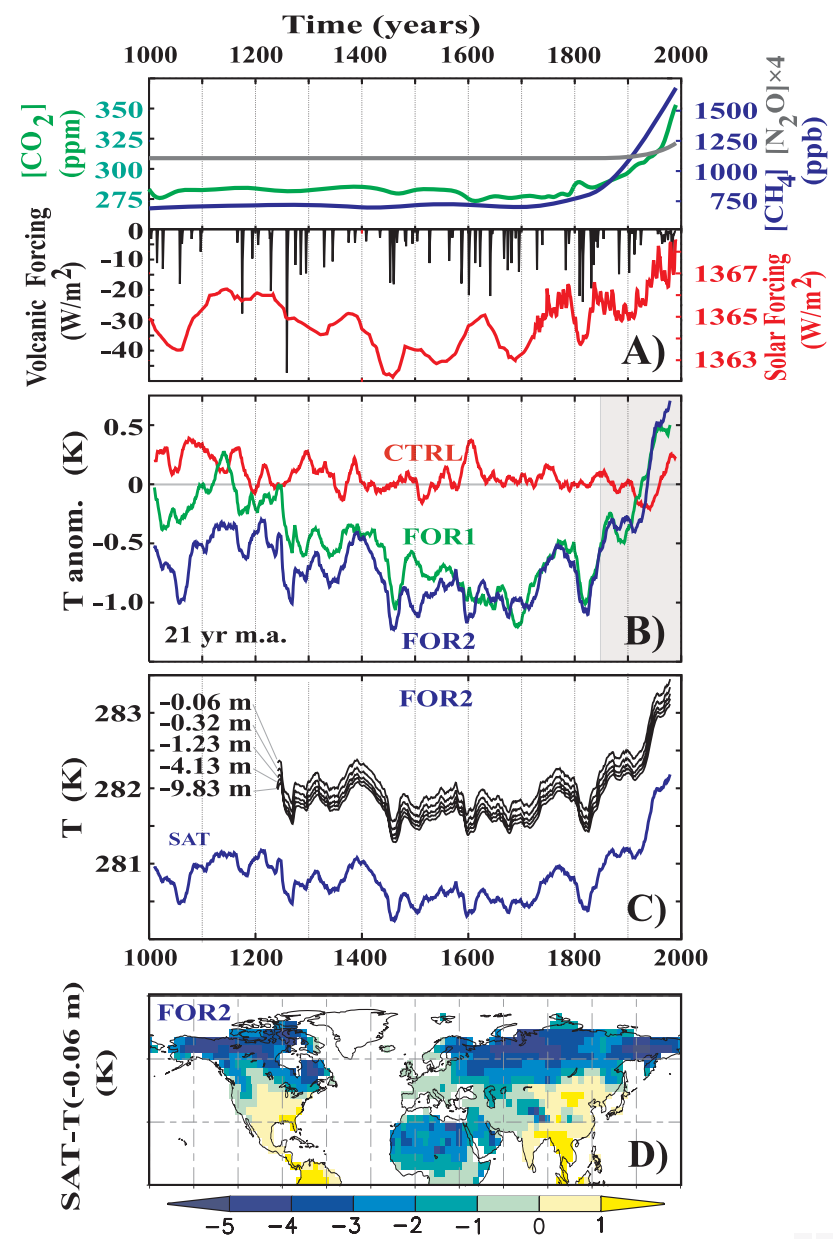

Fig. 1. (A) Estimations of external forcings used to drive the ECHO-G model; (B) northern hemispheric land temperatures in the CTRL and FOR 1, 2 simulations (anomalies are calculated with respect to the last 150 years and shown as 21 year moving average filter outputs); (C) northern hemispheric land SAT and soil temperatures at the various soil model depths in FOR 2; time series of the four deepest soil levels have been shifted $0.05 \mathrm{~K}$ to ease visualization; (D) differences between average SAT and temperature at $0.06 \mathrm{~m}$ below the surface.

(Ammann et al., 2007; Zorita et al., 2007) and with EMIC simulations (Goosse et al., 2005) that trace a very similar climate evolution through the last millennium.

Analysis and validation of the ECHO-G performance in reproducing internal climate variability in CTRL in comparison with instrumental variability can be found in Min et al. (2005a,b); further details can be found in Raible et al. $(2001,2004,2005)$ who analyze North Atlantic atmospheric circulation in other control simulations with the same model. Analyses of different aspects of the forced simulations used herein can be found in the literature (von Storch et al., 2004; Zorita et al., 2003, 2005; González-Rouco et al., 2003a,b, 2006; Beltrami et al., 2006b; Gouirand et al., 2007a,b; Stevens et al., 2007). 
It is also interesting to see how the model simulates the thermal behavior of the subsurface. Figure 1c shows $\mathrm{NH}$ land SAT averages in FOR 2 in comparison with temperature at the five soil model levels. Clearly, the highest frequencies have been filtered out and show considerable differences that will be discussed later in the text; however, at low frequencies (Figure 1c shows 21 yr. low pass filter outputs) subsurface temperatures and SAT share virtually the same evolution (González-Rouco et al., 2003b). Figure 1d illustrates differences between SAT and GST (represented by $T_{-0.06} \mathrm{~m}$ ) over the NH. $T_{-0.06} \mathrm{~m}$ is on average $1.3 \mathrm{~K}$ warmer than SAT, most of this offset resulting from the contribution of thermally isolated areas caused by snow cover. Higher and mid-latitudes in North America and Eurasia present warmer $T_{-0.06 \mathrm{~m}}$ than SAT related to snow insulation. Other regions of the NH like Northern Africa (Southern North America and Southeastern Asia) present warmer (colder) subsurface temperatures resulting from the availability of soil moisture and the balance of radiative and turbulent fluxes at the surface. These issues will be further discussed in Sect. 3.

\subsection{Geothermal models}

Climate reconstruction of GST histories assumes that surface temperature variations propagate into the subsurface following the one dimensional time-dependent heat conduction equation (Carslaw and Jaeger, 1959):

$\frac{\delta T}{\delta t}=\kappa \frac{\delta^{2} T}{\delta z^{2}}$

where $\kappa$ is the thermal diffusivity, which we can assume constant for the typical range of depths of interest for this work, $z$ is depth, and $T$ is temperature. In the absence of transient non-climatic disturbances at the ground surface or systematic perturbations that violate the one-dimensional heat transfer assumption (heat production, topography, ground water flow,variations in thermal properties, etc.), the temperature at depth $z$ is given, at any time, by the combination of the geothermal temperature gradient and the temperature perturbation $T_{t}(z)$ induced by the time varying surface temperatures:

$T(z)=T_{0}+q_{0} R(z)+T_{t}(z)$,

where $q_{0}$ is the quasi steady state surface heat flow density and $R(z)$ is the thermal depth given by $R(z)=\sum_{i=1}^{N}\left(\Delta z_{i} / \lambda_{i}\right), \lambda_{i}$ being the thermal conductivity over the depth interval $\Delta z_{i}$.

Subsurface temperatures can be modeled using surface temperature as an upper boundary condition of an infinite half space. In turn, temperatures at the surface can be thought of as a series of $K$ step changes in temperature such that the subsurface signatures from each step change are superimposed and the temperature perturbation at depth $z$ is given by Mareschal and Beltrami (1992):

$$
T_{t}(z)=\sum_{k=1}^{K} T_{k}\left[\operatorname{erfc}\left(\frac{z_{j}}{2 \sqrt{\kappa t_{k}}}\right)-\operatorname{erfc}\left(\frac{z_{j}}{2 \sqrt{\kappa t_{k-1}}}\right)\right]
$$

where $T_{k}$ is the ground surface temperature, each value representing an average over time $\left(t_{k}-t_{k-1}\right)$, and $\operatorname{erfc}$ is the complementary error function.

This forward model can be used to derive grid point BTPs using simulated surface temperature changes as boundary conditions; as suggested by Fig. 1c and in González-Rouco et al. (2006) the selection of SAT or temperatures at the various soil model levels is of no importance. The forward model is used herein to derive grid-point perturbation profiles $600 \mathrm{~m}$ deep using ECHO-G surface temperature changes as boundary conditions. At each $1 \mathrm{~m}$ depth interval a temperature anomaly is evaluated from the contribution of surface temperature changes using the solution of the heat conduction equation in (2). Equation (2) is however sensitive to the reference temperature selected for the calculation of temperature changes ( $T_{k}$ anomalies). This issue will be further discussed in Sects. 3 and 4.

A singular value decomposition inversion model (SVD; Mareschal and Beltrami, 1992) is used to derive GST histories from grid-point BTPs. The thermal diffusivity value used for the forward and the inversion model applications was the same as in the ECHO-G GCM $\left(0.75 \times 10^{-6} \mathrm{~m}^{2} \mathrm{~s}^{-1}\right)$. The model used for the inversion of each grid point BTP consists of a series of 20-yr step changes in GST history. The eigenvalue cutoff was set in different exercises between 0.025 and 0.3 to select the number of SVD components (Mareschal and Beltrami, 1992; Beltrami and Bourlon, 2004). The singular value cutoff is dependent in experimental practice on the model parameters, model geometry and data noise level, and it varies among BTPs of the same region. Generally, it is convenient to analyze BTPs with as similar geometry as possible to attempt to reduce the effects of different practical resolutions on the ensemble analysis.

\section{Boreholes in the GCM surrogate reality}

One strategy to test methods and assumptions in reconstruction approaches has been to use GCM simulations as surrogates for the real climate evolution. Rather than representing the recent or past climate behavior, the simulations are meant to act as plausible climate realizations compatible with the external forcing imposed to the GCM, and complex enough to incorporate a variety of competing factors that contribute to the realism in the application of the target reconstruction technique (Mann and Rutherford, 2002; Zorita and González-Rouco, 2002; Zorita et al., 2003; Rutherford et al., 2003; von Storch et al., 2004; Mann et al., 2005). Within the geothermal context, this approach has been used to explore potential caveats in the borehole approach to climate reconstruction through assessing various assumptions 
and methodological aspects. We will revisit some of this work along the following section and use it to further illustrate some aspects relevant within the context of GST reconstructions from BTPs.

\subsection{Discussing biases on borehole temperature profiles}

Mann and Schmidt (2003) and Schmidt and Mann (2004) used a 50 year long simulation of the GISS model to explore the effect of snow cover changes on seasonal SAT and GST coupling. They find a good summer link between both variables and report that the winter SAT-GST relationship is disturbed by snow cover. They therefore argue that climate changes in winter SAT might not be as well translated into GST changes as in the warm season. If long term changes in snow cover have occurred during the last centuries these could have caused anomalous changes in GST relative to SAT by altering winter ground surface insulation by snow cover (see also Stieglitz et al., 2003; Zhang, 2005). They argue that if a less intense hydrological cycle would have existed in the LIA due to a more frequent negative NAO phase (Shindell et al., 2001; Luterbacher et al., 2001, 2002a) this would have been consistent with a reduction in winter precipitation and snow cover. Such an scenario would produce anomalous cooling of GST relative to SAT in the coldest phases of the LIA (e.g. LMM). Thus, in the event that climate changes over the past few centuries would have been seasonally different there would be potential for a bias in GST reconstructions that could reflect colder temperatures during LIA than might actually have existed. They suggested that interpretations of past SAT trends from borehole-based GST reconstructions may therefore exaggerate LIA cooling and this could account for the differences of ca. $0.5 \mathrm{~K}$ found among existing reconstructions (e.g. Mann et al., 1999; Huang et al., 2000).

The Mann and Schmidt (2003) arguments were debated by Chapman et al. (2004) using the same GISS simulation and by Bartlett et al. (2005) using observational snow cover, SAT and GST data. Chapman et al. (2004) argue that seasonal differences lead to seasonal offsets in GST and SAT averages and recommend that annual data should be used in such an analysis. In doing so, they report good inter-annual tracking between GST and SAT through the examined 19511998 GISS simulated period. In a follow up study, Bartlett et al. (2005) argue that if the influence of snow on GST is not changing from year to year, the offset would be constant (e.g. Fig. 1d) and with no consequences for SAT and GST tracking. They agree that if snow cover is not stationary its influence on the mean SAT-GST offset varies with time such that long term changes in snow cover may disrupt tracking between the two temperatures by introducing transient and persistent thermal signatures in the coupling. This possibility is examined by considering observations of snow cover changes in North America and their influence on the SAT-GST tracking. They quantified the changes in snow cover onset and duration required to account for the approximately half a degree difference between borehole and multi-proxy climate reconstructions and report that it would be unlikely that changes in snow cover could account for this discrepancy. They find that in the 1970-2002 period, when winter SAT warming was the greatest, snow cover inhibited $0.05 \mathrm{~K} /$ decade of seasonal warming from entering the ground, this being the result of a relatively stationary snow season under changing wintertime SAT.

These issues were also discussed using the millennial control and forced simulations with the ECHO-G model described in Sect. 2.1 (González-Rouco et al., 2003b, 2006) by assessing the relationship between NH SAT and GST at low frequencies. All model simulations showed differences in both variables at high (seasonal and interannual to decadal) frequencies but demonstrated strong coupling between air and ground temperatures at low frequencies essentially as shown in Fig. 1c. This suggested that, within the limits of the reality simulated by the model, changes in surface conditions that perturb ground-air coupling like snow cover or sensible and latent heat fluxes are not strong enough to decouple $\mathrm{NH}$ SAT and GST at long time-scales.

Figures 2 to 4 allow a perspective on the spatial variability of SAT-GST in relation to surface processes like snow and soil moisture changes. The following discussion will be illustrated using data from the FOR2 simulation; FOR1 leads to similar results as described below. Figure 2a shows the average spatial distribution of snow depth in the FOR 2 simulation. The mid- to northern- latitude areas of GST insulation due to snow cover and their correspondence with the negative SAT-GST offsets (Fig. 1d) are apparent. Figure $2 b$ shows the correlation between annual snow depth changes and differences in annual SAT and GST (SAT minus GST at $0.06 \mathrm{~m}$ depth, $\left.T_{-0.06 \mathrm{~m}}\right)$ in the same simulation. Air-ground temperature differences are related to changes in snow depth at inter-annual timescales and broadly dominate in the extratropical regions, thus supporting the influence of snow cover at annual and longer time scales: negative correlations indicate increases (decreases) in snow depth associated with larger (smaller) SAT-GST negative offsets. There is general agreement with the finding by Bartlett et al. (2005) that snow influence on the SAT-GST difference is greatest north of $45^{\circ}$ in North America. Figure 2c and d shows linear trends in simulated snow depth in an extended winter (DJFMA) season for the periods 1700-1990 and 1900 to 1990 . These periods will be used in the following discussion to better emphasize the effect of snow cover and soil moisture trends on SAT and GST temperatures in the last part of the simulation. Values are realistic in comparison to observations (Brown and Goodison, 1996; Frei et al., 1999; Brown, 2000; Brown et al., 2003) and interestingly they show increases (decreases) in snow depth over the northern (middle) latitudes since the simulated LIA to the end of the 20th century. 
A) Snow depth (cm)

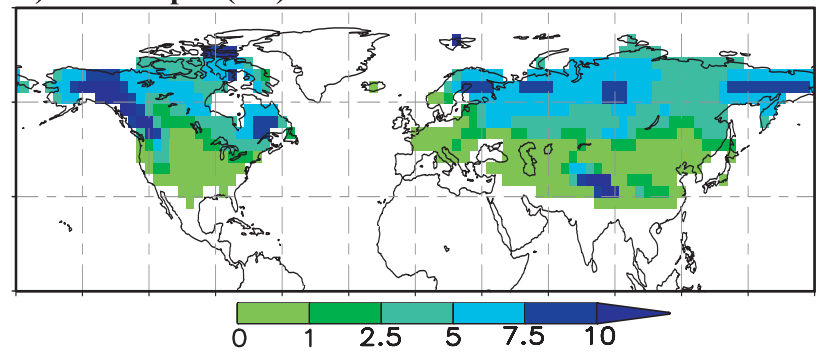

B) Correlation(Sd, SAT-GST)

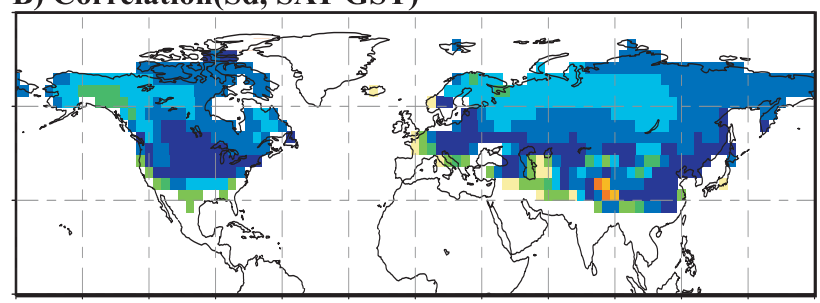

$\begin{array}{llllllllll}-1 & -0.8 & -0.6 & -0.4 & -0.2 & 0 & 0.2 & 0.4 & 0.6 & 0.8\end{array}$

C) Sd trends 1700-1990 (cm/100yr)

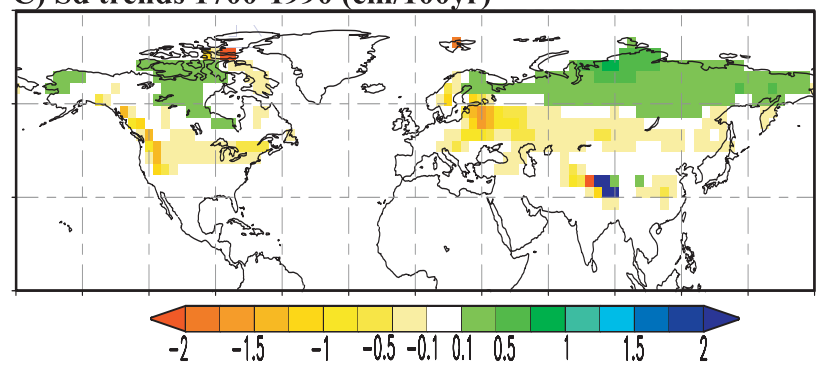

D) Sd trends 1900-1990 (cm/100yr)

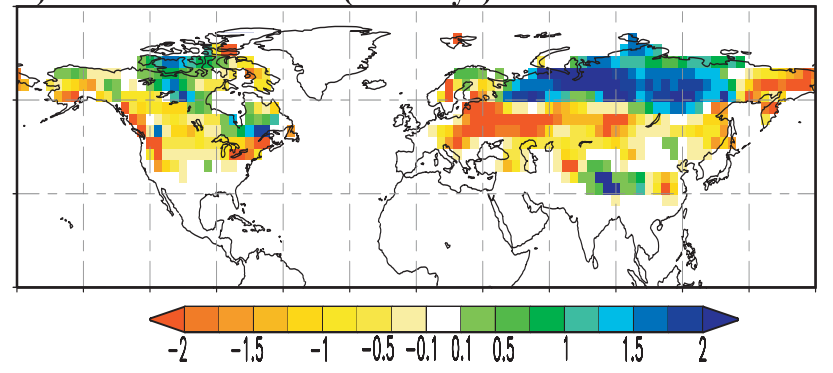

Fig. 2. (A) Average snow depth in the FOR2 simulation (1000 to 1990). (B) Correlation between annual snow depth and SAT-GST differences. (C, D) DJFMA snow depth trends for the period 1700 to 1990 and 1900 to 1990 .

Figure 3 allows the discussion to be extended to the possible influence of soil moisture on air-ground temperature differences. The literature reports interesting changes in soil water content through the 20th century (e.g. Robock et al., 2000; Li et al., 2007; Sheffield and Wood, 2007) and, as in the case of snow depth/cover variations, these have the potential to change the ground temperature response by changing surface latent heat fluxes and the heat capacity of the ground (Hu and Feng, 2005; Kueppers et al., 2007; Taylor

\section{A) Soil moisture (cm)}

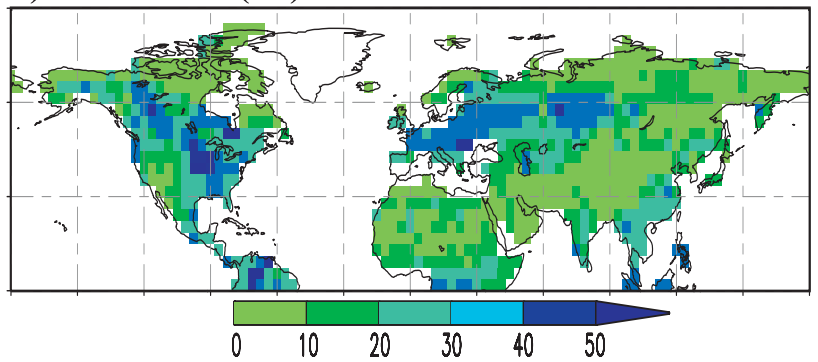

B) Correlation(Sm, SAT-GST)

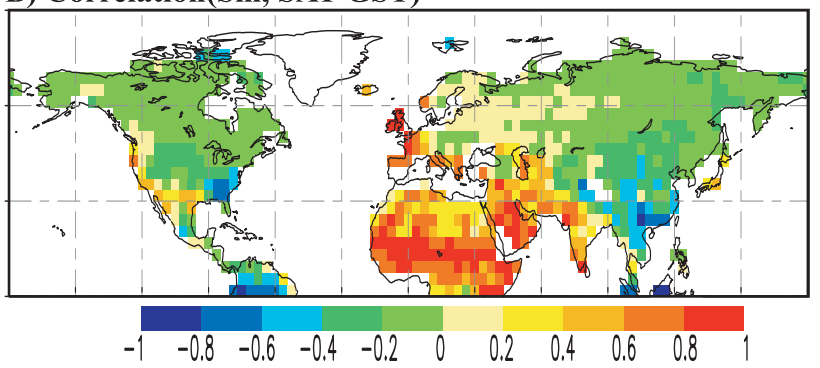

C) $\mathrm{Sm}$ trends 1700-1990 (cm/100yr)

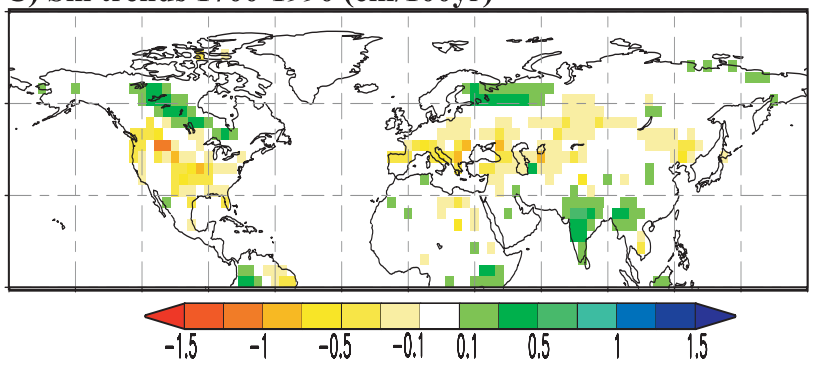

D) Sm trends 1900-1990 (cm/100yr)

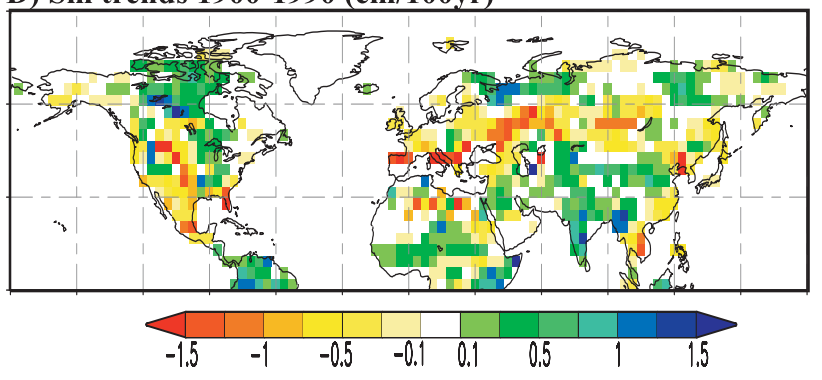

Fig. 3. (A) Average soil moisture content in the FOR2 simulation (1000 to 1990). (B) Correlation between annual soil moisture and SAT-GST differences. (C, D) Annual soil moisture trends for the period 1700 to 1990 and 1900 to 1990 .

et al., 2007). The average distribution of wetness (Fig. 3a) depicts areas of larger water content over Europe, the western Siberian plains, Southeastern Asia and the tropical areas of the Americas and in Eastern North America. Correlations between annual soil moisture and SAT-GST differences (Fig. 3b) illustrate the importance of soil moisture changes on air-ground temperature coupling in the lower sub-tropical and tropical regions complementary to that of snow depth changes in the northern half of the NH (Fig. 2b). Soil mois- 
A) SAT-GST trends 1700-1990 (K/100yr)

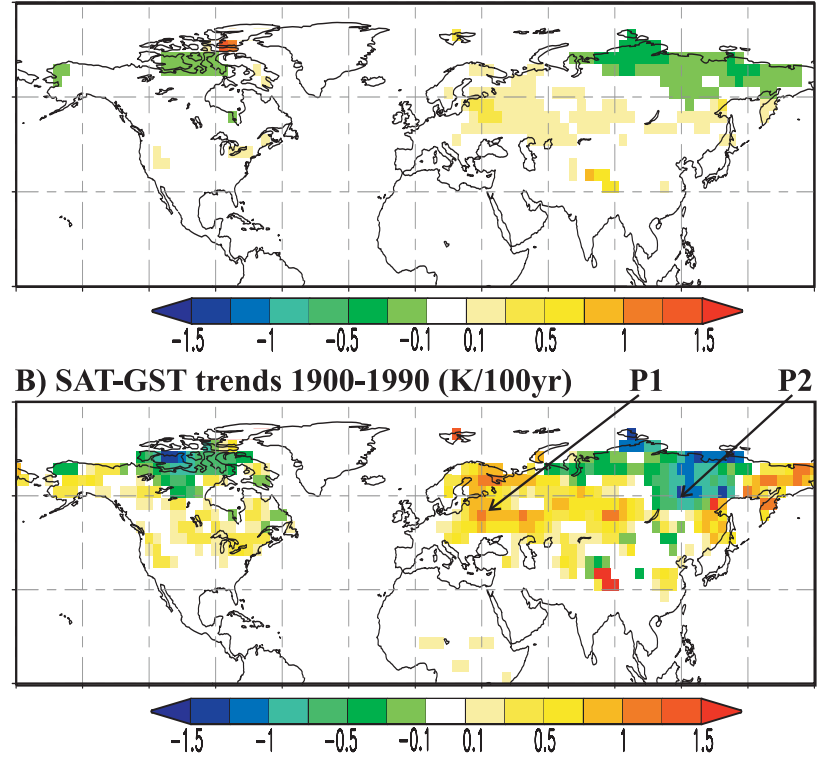

C)

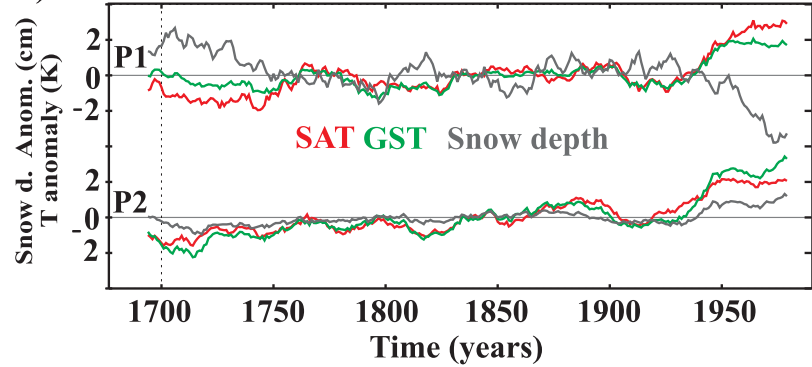

Fig. 4. Linear trends (K/100 yr) for annual SAT minus GST $\left(T_{-0.06 \mathrm{~m}}\right)$ differences for the period 1700 to 1990 (A) and 1900 to 1990 (B). (C) Evolution of snow depth, SAT and GST anomalies during the last three centuries at the $\mathrm{P} 1$ and $\mathrm{P} 2$ locations highlighted in panel B; anomalies are calculated with respect to the average of the period 1700-1990 and shown as 21 year moving average filter outputs. All plots show results for the FOR 2 simulation.

ture changes show opposite sense to those in absolute temperature differences at the surface, i.e., increases (decreases) in soil moisture tend to reduce (increase) the thermal difference between SAT and GST. In the areas of positive (negative) SAT-GST offset in Fig. 1d like eastern USA and eastern Asia (northern Africa and western USA) this translates into negative (positive) correlations in Fig. 3b. This relation suggests that soil moisture could also be a factor in producing long term changes in ground-surface coupling and thus cause a bias in borehole temperatures. Figure $3 \mathrm{c}$ and d show linear regression coefficients for the period 1700 to 1990 and 1900 to 1990 in annual soil moisture as simulated in FOR 2. These values are in the range of observed estimations for the second half of the 20th century (e.g. Robock et al., 2000; Li et al., 2007; Zhang et al., 2008). The simulated changes indicate for instance increases of soil moisture in Northern Europe and decreases in mid-latitudes like the Mediterranean. These changes, as well as those shown above in snow depth would be consistent with an intensification of the hydrological cycle, thus, also compatible with a transition to a more zonal circulation (positive phase of the NAO) in the North Atlantic since the LMM as hypothesized by Mann and Schmidt (2003). In fact, FOR 1 and FOR 2 show long term transitions to a more zonal circulation from the LIA to the end of the simulations (e.g. Zorita et al., 2005).

Figures 2 and 3 present a geographically complementary view of the domains of relevance of snow depth and soil moisture for air-ground coupling as well as a non stationary view of long term changes in both variables. However, snow cover and soil wetness changes are not the only factors with potential to disrupt the SAT-GST relation. Other factors introducing long term changes in soil radiative insulation and surface turbulent and radiative fluxes (e.g., vegetation or land use changes) can potentially bias GST with respect to SAT variations. Examples are vegetation and land use changes, that are included in some high complexity GCM simulations (Tett et al., 2007) and are not considered in the simulations discussed herein and could potentially affect GST at long time scales (Bonan et al., 1992; Lewis and Wang, 1998; Bauer et al., 2003; Nitoiu and Beltrami, 2005; Davin et al., 2007; Xu et al., 2007). Thus, these are issues that deserve attention in the future.

Long-term trends in SAT-GST differences during the simulated 20th century, (Fig. 4) show positive values indicating increases of SAT relative to GST over mid-latitudes and GST warming relative to SAT (negative trends) at northern latitudes. There are no trends simulated in the areas of sensitivity of SAT-GST to soil moisture (Fig. 3b), thus the response suggests a relation with snow depth changes. Actually, there is regional agreement in broad spatial features in Figs. 2d and 4d like increasing snow depth (increasing the SAT-GST offset) over northern Eurasia and North America and decreasing snow depth (decreasing the SAT-GST negative offset) over the mid latitudes and eastern Russia. Rather than long-term continuous changes, these linear trends arise in the simulations due to multi decadal changes during the second half of the 20th century. Figure 4c shows an example of SAT, GST and snow depth evolution at two characteristic points. The larger decreases (increases) in snow depth in the last decades in P 1 (P 2) lead to relative GST cooling (warming) with respect to SAT changes due to increased exposure (insulation) to winter surface fluxes. The largest departures between SAT and GST anomalies go along with the largest changes in snow depth. While in P1 GST would underestimate changes in SAT, in P 2 the contrary would happen.

Therefore, Fig. 4 shows that large changes in snow depth/cover can modify the SAT-GST relationship. The changes simulated by the model are reminiscent of those found in observations (e.g. Brown, 2000) in as much as they reflect larger changes of snow cover for some regions during the last decades of the 20th century. Such decadal 
trends should have little influence on the estimation of multicentury trends that are imprinted on borehole BTPs to depths of several hundred meters. Thus, as suggested by Pollack and Smerdon (2004), it is not trivial to make a case for a systematic bias in subsurface temperatures due to these processes. In the surrogate reality of the model simulations, in spite of the changes in all variables represented by Figs. 2 to 4, there seems to be a negligible impact in the reconstruction of $\mathrm{NH}$ GST histories from simulated BTPs (González-Rouco et al., 2006).

It is worth noting that previous discussions and exercises replicating the borehole approach to climate reconstruction (e.g. González-Rouco et al., 2006) do not demonstrate that the method is correct. The arguments rather lean on a null hypothesis that the methodology is actually competent in its purpose and the evidence either reveals itself to be consistent with this statement or rejects it if results point in the opposite direction. Also, in this line of argumentation, it is not relevant whether the model simulations reproduce the exact real past climate trajectories of the involved variables. Though desirable, most likely this will not be the case since the evolution of these variables will be largely subject to internal, non-forced, climate variability and due to limitations in model resolution and parametrizations (von Storch, 1995; Räisänen, 2007) to reproduce detailed aspects of snow depth and soil moisture dynamics (Brown, 2000; Déry and Wood, 2006; Robock and Li, 2006; Li et al., 2007). The relevant issue in this approach, however, is whether the magnitude and spatial variability of simulated changes are realistic enough to assess whether changes in SAT-GST coupling within the simulated reality would produce long-term biases in BTPs. In the case discussed herein, the model simulations do not show evidence to distrust the skill of the method in retrieving hemispheric estimates of past temperature changes. At the regional scales, however, the weight of trends in snow depth or other surface perturbations might be larger and not lead to an overall balance as at hemispheric scales; an example addressing regional scales will be shown in Sect. 3.2.

\subsection{Other methodological aspects}

Beyond the questions raised above concerning SAT-GST coupling, Mann et al. (2003) further address various issues concerning observational and methodological aspects that could account for the differences between borehole-based and other proxy-based climate reconstructions. Two major problems were discussed: (i) the influence of spatial aggregation and gridding of GST reconstructions from BTPs and of latitudinal area weighting to produce a $\mathrm{NH}$ temperature reconstruction; (ii) the apparent failure in GST reconstructions to reproduce a spatial structure of changes comparable to that of SAT throughout the instrumental period. Mann et al. (2003) developed a NH temperature reconstruction for the last five centuries using the Huang et al. (2000) set of inverted NH BTPs in an optimal signal detection approach which was more in agreement with previous multi-proxy reconstructions (Mann et al., 1999). These results were criticized by Pollack and Smerdon (2004) who examined the impact of aggregation and area weighting for various grid resolutions on the spatial consistency of GST and SAT trends. They concluded that low occupancy cells obscured the relation between SAT and GST and demonstrated the existence of spatial consistency in both sets of variables. In a revision of their initial work Rutherford and Mann (2004) would later agree that gridding and area weighting do not resolve the differences between borehole and other proxy reconstructions.

In addition to gridding and area-weighting, other possible methodological and observational aspects that may degrade borehole reconstructions as representative indicators of SAT changes were discussed by Mann et al. (2003) and Pollack and Smerdon (2004). Two of these are borehole site geography and logging dates. Both of these issues can produce unclear biases in the datasets that could affect GST reconstructions. The geographical distribution of boreholes is centered mostly in mid-latitudes and this could introduce a climatological bias in GST reconstructions. As for logging dates, the borehole data set (Huang and Pollack, 1998) was compiled since the 1960's and different regions display some heterogeneity in logging dates (see Fig. 5c). This can produce biases by under-representing trends in regions where BTPs were logged earlier. While a geographical bias would potentially exaggerate warming by misrepresenting low latitude regions and oceans that would warm less, the bias in the logging dates would presumably under-represent warming by excluding the later 20th century decadal warming in regions where BTPs were logged earlier (Pollack and Smerdon, 2004).

The potential bias in the BTP geographical distribution was explored in the ECHO-G model simulations (GonzálezRouco et al., 2006) by comparing the model response using the whole array of model grid-points and a reduced mask overlapping with areas where actual BTPs are available. Both spatial samples lead to virtually identical results, thus supporting the present distribution of BTPs as a viable sample for estimating terrestrial SAT variations. GonzálezRouco et al. (2006) further illustrated the potential of the borehole methodology to produce GST reconstructions using a forward model (see Sect. 2.2) to simulate synthetic BTPs within the model world and subsequently inverting and averaging them to produce a hemispheric GST reconstruction that could be compared to the model simulated surface temperature.

This approach will be revisited in the remaining part of this section to illustrate how the method can be used to address the potential influence of logging dates and BTP depth on borehole climate reconstructions. We will focus on North America as the example case where both variables show considerable spatial variability as depicted in Fig. 5; similar results should be expected for other regions. 


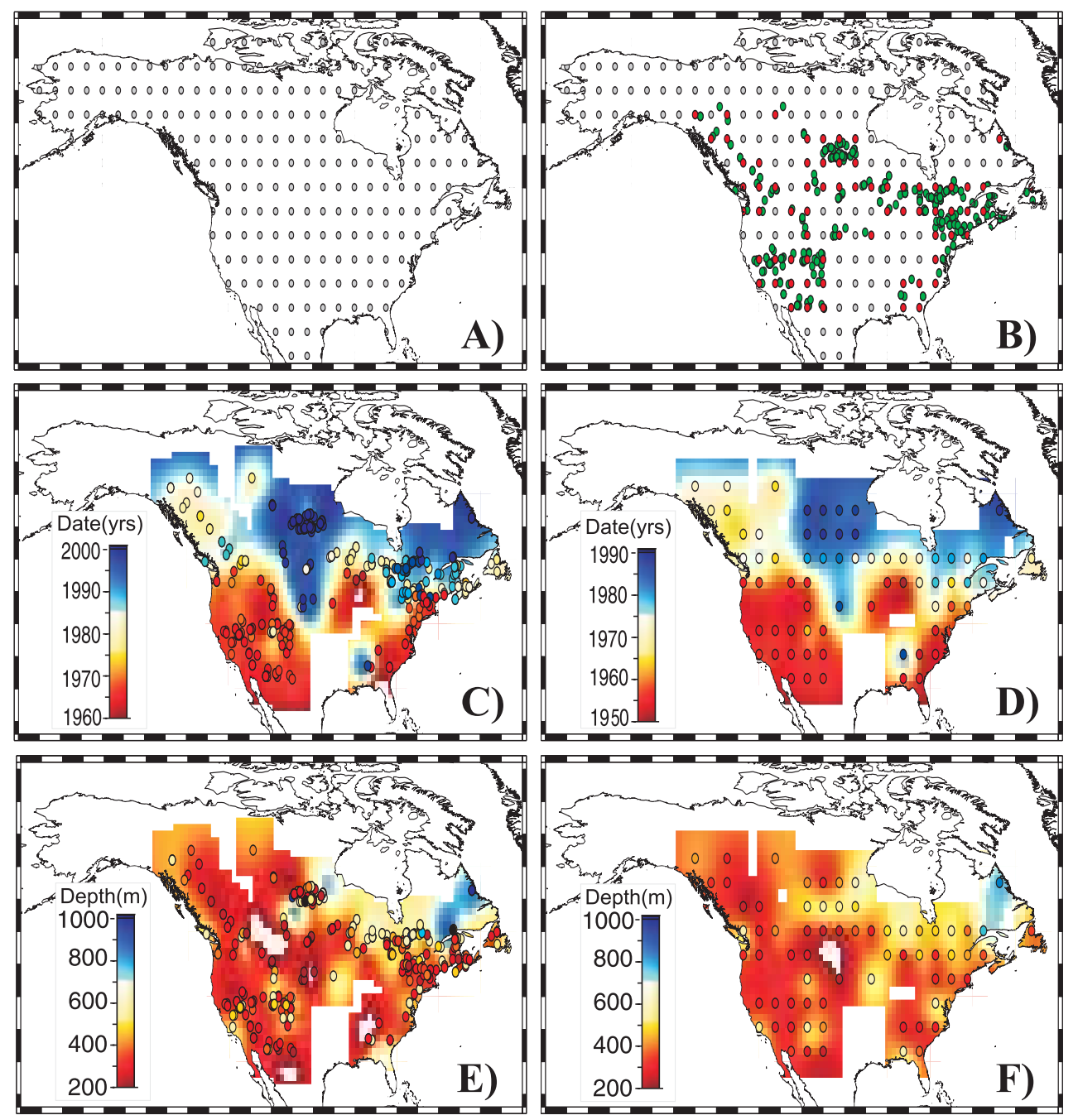

Fig. 5. (A) ECHO-G grid over North American land; (B) as in (A) and showing a selection of model grid points (red) which are closer to real borehole locations (green). (C, E) Distribution of logging dates and depths in the borehole dataset and replicated distributions in the ECHO-G simulations (D, F). Interpolated variable fields are represented with shading to facilitate visualization of spatial variability.

The original model grid (gray dots in Fig. 5a) was reduced to retain a subset of grid-points that resembles the observational borehole network (red and green in Fig. 5b, respectively).

BTPs were simulated at each location using GST anomalies at the deepest $(-9.83 \mathrm{~m})$ soil model level. Anomalies were calculated with respect to the full period of simulation and diffused downwards into the ground using Eq. (2) as described in Sect. 2.2. This was done for the full model grid and for the subset of selected grid-points.

These simulated profiles represent a perfect world in terms of temperature perturbation profiles for which the SAT is known. These profiles can be inverted in order to test the potential of inversion models to retrieve GST histories in a process that mimics the borehole approach to climate reconstruction. Additionally, the profiles can be further degraded making them more similar to real borehole temperature vs. depth anomalies and test the effect of degrading factors on the final reconstructions. Thus, the smaller grid-point subset was further deteriorated to incorporate a more realistic representation of possible biases related to logging dates and borehole depth.

The distribution of logging dates in the borehole dataset is spread over the last 40 to 50 years (Fig. 5c); overall the earlier measurements where taken in the USA and the more recent logs are distributed mostly over Canada. The potential impacts of this different distribution have been discussed in the previous section. This geographical spread is replicated within the model world over an equivalent range of 40 years (Fig. 5d), ending in 1990 in order to accommodate the length of the model simulations. Model grid point series were trimmed according to this distribution before diffusing 
them into the ground. In this way, the simulated BTPs mimic within the model world different measurement moments. For the control simulation these dates are arbitrary since there is no correspondence to real years and were assigned in such a way to reproduce an equivalent loss of data at the end of the simulation as it was done for the forced runs.

A further degradation step consisted of shortening the simulated BTPs according to the real depth distribution shown in Fig. 5e and replicated in Fig. 5f. Though this distribution ranges over a depth of $1000 \mathrm{~m}$, in practical terms only changes on the first ca. $400 \mathrm{~m}$ (see Fig. 6a) can have some effect, since below this depth the simulated perturbation profiles virtually converge to zero. This approach attempts to address the impact of losing part of the climatic history in areas where boreholes are shallower.

The resulting sets of profiles are shown in Fig. 6a where the larger size of the original set of profiles (light shading) is highlighted in comparison to the smaller subset (dark shading) which is decimated and corrupted by date and depth irregularities. The forced simulations present a tendency to larger warming in the top ca. $150 \mathrm{~m}$ representing the trends from the LIA to present. Below this depth, between ca. $300 \mathrm{~m}$ and $200 \mathrm{~m}$, some cooling is evident that relates to the transition from the simulated MWP to the LIA. Also, in comparison to the control run, the depth of warming onset is deeper in the forced than in the model simulations. In the control BTPs this shallower warming can be attributed to trends caused by internal variability at the end of the simulation (see CTRL in Fig. 1b). The simulated BTPs were inverted using SVD (Mareschal and Beltrami, 1992) to obtain local GST histories and the mean was area-weighted over the whole domain. For each local GST history, prior to obtaining the spatial average, temperatures were kept constant since the logging date (Fig. 5d) until 1990 in order to mimic published exercises (e.g. Harris and Chapman, 2001). This is a rather conservative scenario since in the real world instrumental or reanalysis data are available and can be used to fill the gap after the logging date in a more accurate fashion. The cutoff level used for the SVD-eigenvalues in this exercise was 0.025 .

Figure $6 \mathrm{~b}$ compares the low frequency evolution of North American SAT in each of the simulations and the latitudeaverage of the inverted GST histories, both for the complete grid (solid lines) and the perturbed subset (dashed lines); differences between both GST inversions are highlighted.

The three GST histories successfully recover the lowfrequency changes in North American SAT. The broad differences between the control and forced simulations are recovered, including the different level of MWP warming in FOR 1 and FOR 2. The differences between the full gridpoint net and the perturbed subset are negligible in the context of the low frequency variability reproduced by the inverted histories; also, they are on the range of variability of typical methodological uncertainties in the SVD approach (e.g. Beltrami et al., 1992; Beltrami and Bourlon, 2004). Thus, Fig. $6 \mathrm{~b}$ lends support for the borehole reconstruction approach in recovering low frequency changes of past temperature and suggests that the potential effects of variability in logging dates and depths as simulated here are minor and will hardly explain offsets between borehole based and other proxy reconstructions.

Nevertheless, this exercise rests on some assumptions that are worth discussing. Since this approach only simulates temperature perturbation profiles, i.e. the $T_{t}(z)$ terms in Eq. (1), all the potential problems related to the separation of the climate transient, $T_{t}(z)$, from the geothermal gradient in Eq. (1), $T_{0}+q_{0} R(z)$, are overlooked. Additionally, there are at least two relevant issues when separating the geothermal and climatological information in BTPs: the actual depth of the profiles and the existence of noise. These two factors contribute in practice to blur the smooth transition depicted between the MWP and the LIA in Fig. 6b; some interesting exceptions exist though (see Demezhko and Golovanova, 2007, in this issue).

The treatment given to borehole depth in Figs. 5 and 6 addresses the fact that shallower boreholes miss a part of the climate history recorded deeper into the ground but skips the problems of discriminating the geothermal from the climatological signal in shallower boreholes which have not fully met the geothermal equilibrium gradient. Thus, the previous results assume that there is a perfect separation between both types of signals and addresses only potential problems related to the subsequent processing of perturbation profiles.

Borehole noise is another issue that further complicates both the inversion of perturbation profiles and the discrimination between the geothermal background and the climate transient. The latter problem could be easily addressed by adding some realistic noise to the temperature profiles in Fig. 6 and continuing with the other steps of the methodology. Therefore, an additional improvement of the approach that can be considered in future work is the simulation of a random and realistic spatial distribution of geothermal gradient values and noise that will allow for a more realistic reproduction of all the steps of the procedure. However, it is not clear that the inclusion of these features will lead to large biases in the recovered GST histories since errors in separating the terms in Eq. (1) at each BTP should randomly distribute contributing to produce under- and over-estimations of surface temperature.

The impact of noise in perturbation profiles is in practice overcome by considering smoother solutions to the heat diffusion equation. In the case of the SVD inversion approach used herein this implies the use of larger eigenvalue cutoff levels, thus retaining less information from the measurements. This avoids unstable solutions produced by overweighting errors in the eigen modes (see discussion in Beltrami and Mareschal, 1995; Beltrami and Bourlon, 2004). The effects of this can be observed in Fig. 6c where various GST histories corresponding to cutoff levels between 0.025 and 0.3 are shown for the case of the FOR 1 simulation. The 0.025 value is rather low and appropriate for noise-free pro- 

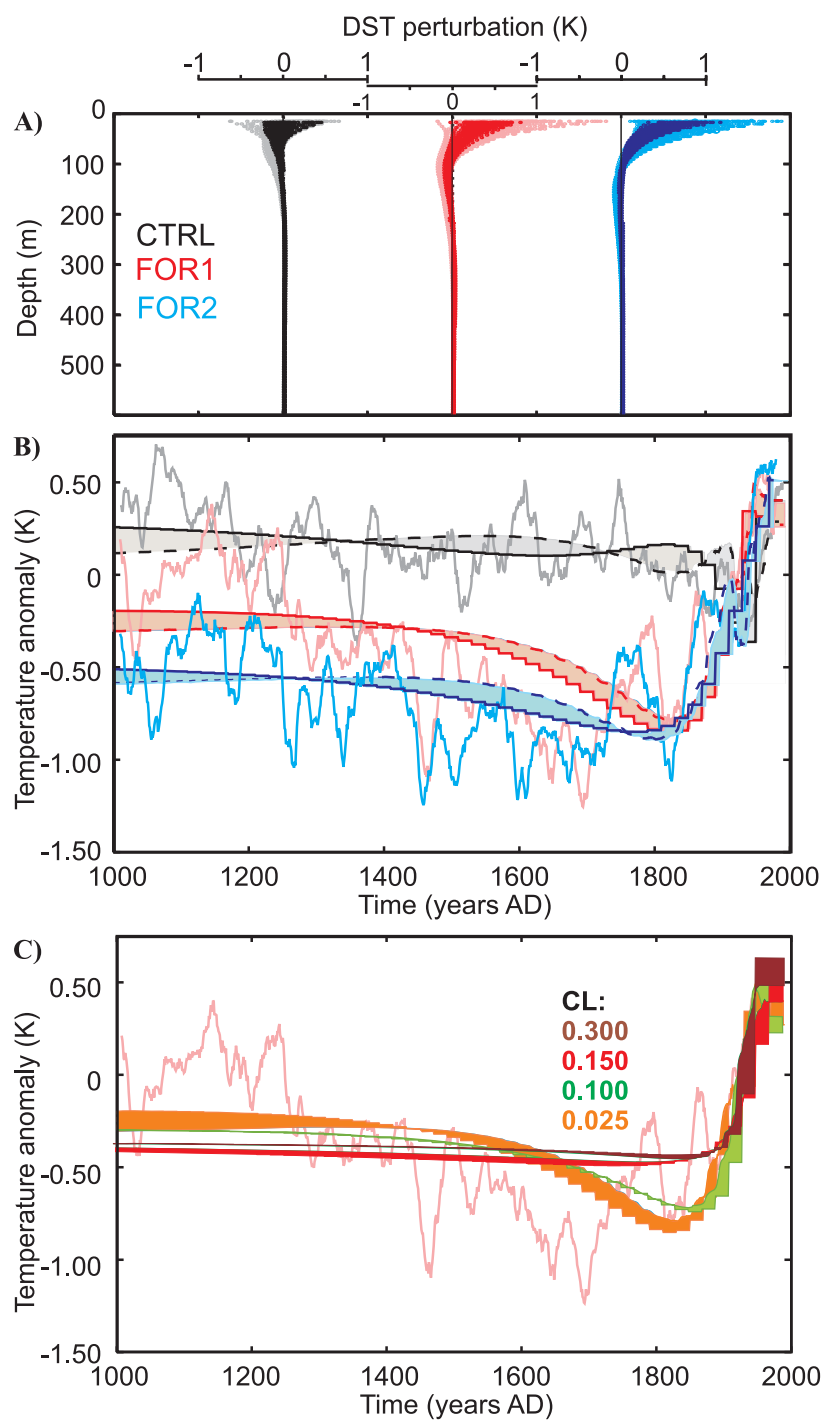

Fig. 6. (A) Forward model simulation of BTPs with GST in the complete North American grid point net (light shading) and driven with the subset of selected grid points (dark shading). (B) 21 year low pass filtered SAT over North America and GST histories recovered from the inversion and latitude-weighted average of BTPs in (A). (C) Solutions for the FOR 1 simulation under different eigenvalue cutoff levels (CL). Anomalies are calculated in (B) and (C) with respect to the last 150 years in each simulation.

files whereas values between 0.1 and 0.3 are typical of real profiles with the presence of noise (Beltrami and Bourlon, 2004).

The provided solutions show a progressive decrease of the differences between the original complete set of GST gridpoint BTPs and the date and depth perturbed subset. Also a progressive loss of skill in depicting the warming from the LIA to the MWP is observed in addition to less cooling from the simulated 20th century to the LIA. Interestingly, this behavior suggests that a more realistic replication of the bore- hole method leads to under- rather than over-estimation of past climate variability and, in particular, LIA cooling.

A last comment in this discussion concerns the assumption implicit in calculating temperature anomalies with respect to the full period of simulation before producing BTPs. This apparently innocuous step is arbitrary and not free from quite strong assumptions since the selection of a reference period, and thus a mean temperature reference value for the calculation of anomalies produces important changes in the simulation of BTPs. However, the selection of a particular reference is irrelevant if the analysis rests on taking for granted that a perfect discrimination between the geothermal gradient and the climate transient is possible. Under this assumption, the analysis starts by adopting the simulated perturbation BTPs as valid and addressing all subsequent aspects of the methodology. Decisions concerning the selection of a mean temperature reference level to calculate anomalies bear more importance in the comparison of observational and simulated BTPs. Therefore, this will be further discussed within the context of the next section.

\section{Simulations and observations}

Section 3 was focused on some questions that can be addressed by using models as a surrogate for reality. However it is also pertinent to analyze the degree of realism of GCMs in reproducing some aspects of reality. In the geothermal context there are at least two directions along which such questions can be posed: 1) the agreement between GCM simulations and observed BTPs; 2) the level of fidelity with which GCMs can recreate the details of the air-ground temperature coupling at local scales. The first point targets the comparison of model simulations and borehole paleoclimatic reconstructions or BTPs. The second question attempts to address whether the degree of realism of the simulated land surface processes is adequate both in the paleoclimatic and in the future climate change context.

\subsection{Simulated and observed borehole temperature profiles}

Reliable projections of future change require that climate models prove effective in simulating past changes in broad agreement with evidence provided by climate reconstructions. Advances in the convergence between simulation and reconstruction approaches will require reducing various types of uncertainties on both sides (Jansen et al., 2007; Hegerl et al., 2007b). Joint analysis of climate reconstructions, model simulations and estimated past external forcing can illustrate the level of agreement between model results and reconstructions (Jones and Mann, 2004; Zorita et al., 2004; Moberg et al., 2005; Mann et al., 2008), but also to try to constrain the range of climate sensitivity (Hegerl et al., 2006) and to attribute past changes registered in millennial 
climate reconstructions to particular external forcings (Crowley, 2000; Bauer et al., 2003; Hegerl et al., 2003).

In the context of borehole climate reconstructions, first steps have been taken in designing a means of comparison of the information provided by BTPs with model simulations. Beltrami et al. (2006b) compared the output of the ECHO$\mathrm{G}$ simulations presented herein with BTPs in four regions over Canada. It was found that in all cases model subsurface anomalies were in better agreement with observed profiles than the synthetic profiles derived from the control simulation. Stevens et al. (2008) arrived at the same conclusion in an extension of the analysis to the whole of North America in which alternative ways of comparing real and simulated profiles are explored.

Stevens et al. (2008) and Beltrami et al. (2006b) also highlighted a seemingly qualitative agreement in the east-west arrangement of trend in the observed and in the synthetic boreholes from the forced simulation over northern North America. Smaller (larger) amplitude of warming has been reported for the western (central and eastern) parts of Canada (Majorowicz et al., 2002) and, in particular, changes from the western to the eastern side of the Cordillera have been noted (Wang et al., 1994; Pollack and Huang, 2000). Figure 7 provides a spatial perspective into the trends simulated by the ECHO-G model for the period 1700 to 1990 that allow comparison with the observational trends shown in Pollack and Huang (2000). In spite of different internal non-forced variability in each simulation, both model integrations produce a remarkably similar pattern with smaller trends over western Canada and larger trends in the central and eastern territories. The large-scale temperature response in these model simulations is shown in Zorita et al. (2005) and can be described as a land-ocean thermal contrast superimposed to regional trends that are associated with changes in the main modes of atmospheric circulation. Over North America most of the main land and the regions usually covered by perennial snow the model simulates larger warming in the continent with diminishing amplitude towards the ocean and with a regional minimum in western Canada that would be consistent with borehole observations. This agreement may well be coincidental and it is premature to claim that the observed warming pattern can be attributed entirely to the response to external forcing. However, given that the pattern seems to be robust in both ECHO-G simulations, it is interesting to further explore some broad features of agreement and disagreement between Fig. 7 and observational evidence.

In addition to the east-west arrangement of amplitude trends over Canada, the simulated warming is largest over the northern areas of Alaska, also consistent with borehole observations (Lachenbruch and Marshall, 1986). The western USA displays however, trends that are comparable to those in central and eastern Canada, a feature that contradicts the experimental evidence for the western USA (e.g. Harris and Chapman, 1995) that has shown less warming than central and eastern Canada. It can be speculated that most of the boreholes over this area correspond to early logs in the dataset mostly from the 1960's and 1970's (see Fig. 5c), that fail to register the posterior warming (Stevens et al., 2008). Thus, if the pattern in Fig. 7 would be supported by other model simulations and further evidence, this rationale would encourage the up-to-date borehole sampling over this area of North America.

Beltrami et al. (2006b) and Stevens et al. (2008) suggest that observed BTPs can be compared to model paleoclimatic simulations by diffusing the GCM simulated temperature signal into the ground by using a forward model in order to generate subsurface synthetic BTPs that can be assigned to real BTPs.

However, this comparison is not straight forward since it requires the establishment of some assumptions to calculate model SAT or GST anomalies which are subsequently forward-diffused into the ground.

Usually this has been done by selecting a temporal reference period so that anomalies are obtained with respect to the mean temperature during this period. Such a selection is not evident both because boreholes integrate the influence of climatic events before the start of the 1000 year ECHO-G millennial simulations and also because these simulations do not necessarily yield a detailed representation of past temperatures (Räisänen, 2007). In fact, Figs. 6 and 7 show that different model simulations provide climate realizations that are not identical and that ultimately translate into slightly different synthetic BTPs.

Beltrami et al. (2006b) took a simplified approach and selected the mean of the whole period of simulation (1000 to 1990) as the reference to calculate anomalies. However, this choice is as arbitrary as any other selection since it turns out that the choice of the reference period, and thus the reference mean temperature, influences the shape of the forward simulated BTPs. Figure 8 shows an example of the impact on the shape of diffused profiles for a set of selected reference periods using the SAT series from FOR 2 at an arbitrary grid point in central North America $\left(46.39^{\circ} \mathrm{N} 96.5^{\circ} \mathrm{W}\right)$ as a boundary condition. In the various profiles, anomalies are calculated with respect to the different means of the selected reference period.

The problem illustrated in Fig. 8 can be related to that of comparing instrumental time series and observed BTPs (Harris and Gosnold, 1999; Harris and Chapman, 2001; Harris, 2007). Also in this case the selection of a mean temperature reference is not self-evident because boreholes integrate a much larger climate history that the approximately twocentury-long instrumental period or even the 1000 year GCM paleoclimatic simulations considered here.

This makes the climate signal recorded in boreholes and that diffused into synthetic BTPs not fully comparable since the existence of an influence corresponding to longer time scales (i.e. multi millennial or glacial to inter-glacial) cannot be ruled out in experimental BTPs of the typical depths involved herein. 


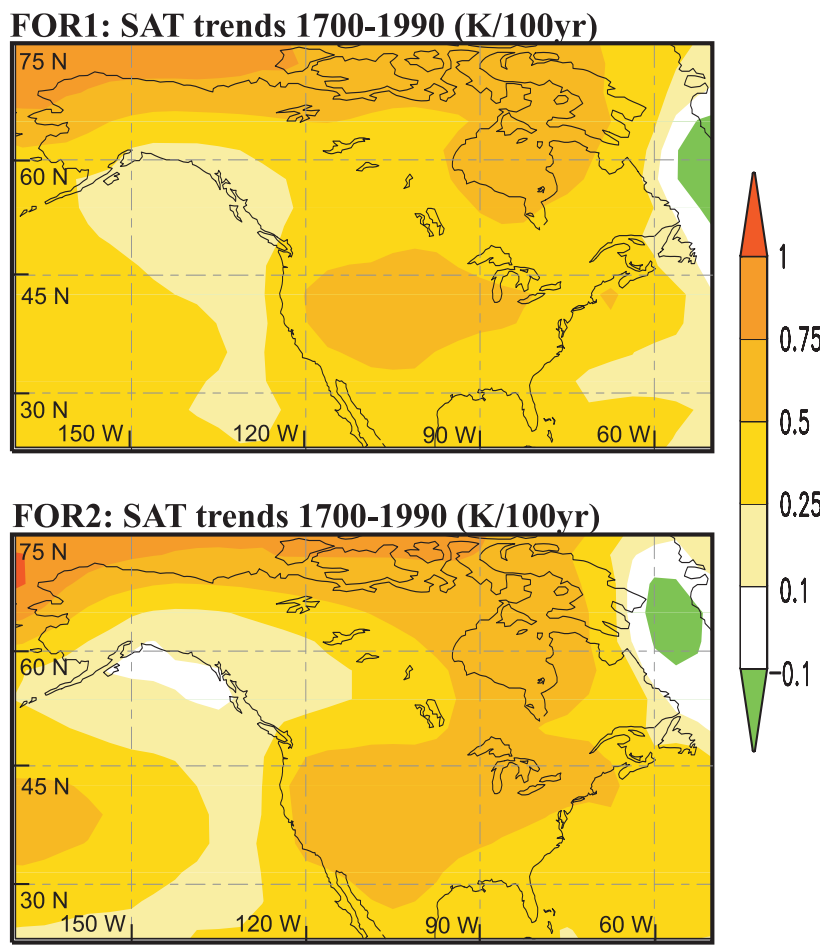

Fig. 7. Annual SAT trends (K/100 yr) for the period 1700-1990 AD in the FOR 1 and FOR 2 simulations for the area of North America.

The contribution of this background or pre-observational climate has been taken into account in exercises of comparisons of real BTPs with instrumental data making use of the pre-observational mean concept (see Harris, 2007, in this issue and references therein). From this perspective the selection of an unknown reference period with respect anomalies should be calculated is avoided and substituted by a search for an average temperature reference level that represents the contribution of the pre-observational/instrumental local climate to the observed subsurface thermal regime.

The use of such an approach in the case of instrumental time series and borehole temperature profile comparisons is founded in the assumption that GSTs and SATs perfectly track each other. The search for the appropriate preobservational reference temperature is performed through minimizing a measure of similarity between the diffused instrumental time series of temperature anomalies and the observed borehole temperature profiles. The selected value not only provides minimal error by definition, but this error is also expected to be very small in magnitude due to the assumed GST and SAT coupling. In the case of the comparison between observed and synthetic boreholes this rationale cannot be invoked since millennial long GCM simulations cannot be regarded as a detailed representation of true past SAT recorded in real boreholes. Thus, the strategy of searching for a minimal separation between real and simulated borehole temperature profiles cannot be designed under the ra-

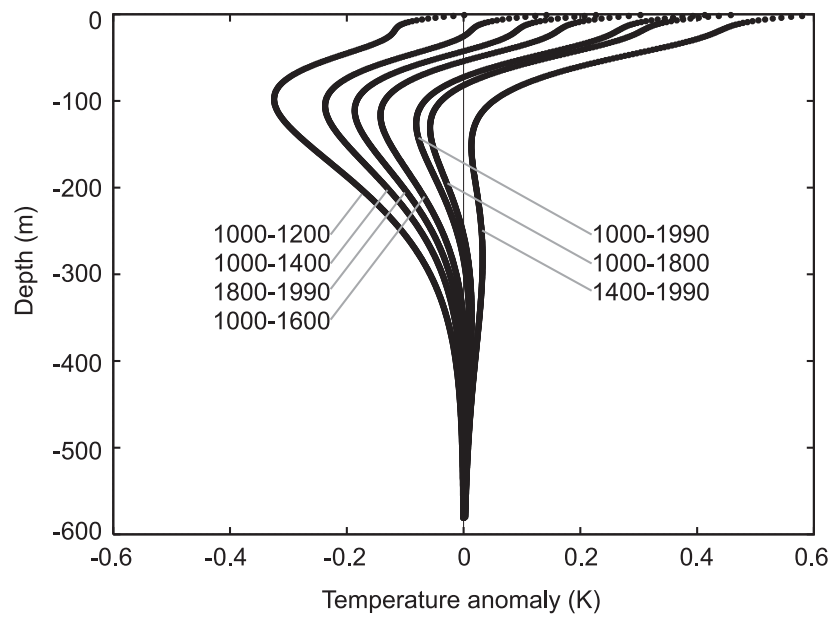

Fig. 8. Forward simulated BTPs using the SAT series at grid-point in central North America $\left(46.39^{\circ} \mathrm{N} 96.5^{\circ} \mathrm{W}\right)$ in the FOR 2 simulation. Each profile is obtained from anomalies calculated with respect to the reference period indicated in the plot.

tionale that the GCM-simulated thermal regimes will necessarily match the observed ones as in the comparisons between real boreholes and instrumental data. Yet, in the absence of other reasonable approaches this is still a useful guide that allows for scanning over a wide range of possible mean temperature reference levels with respect to whic simulated anomalies can be calculated and forward diffused into the ground.

In this fashion, a family of curves can be generated for each selected region by forcing the forward model by simulated SATs series of anomalies considering a range of mean temperature reference levels. This variability in the synthetic BTPs illustrates the uncertainty in the selection of a temporal reference period, or associated mean temperature reference level, in each model simulation. The similarity between synthetic and observed BTPs can be quantified through various criteria which can serve as a means of model-data comparison. This strategy was used in Stevens et al. (2008) using three measures of distance between simulated and real BTPs: the root mean square error between pairs of synthetic and observed profiles, the depth at which the LIA cooling is recorded in BTPs and the amplitude of temperature change from this depth to the surface. Results showed that the forced simulations presented depths of pre-industrial cooling and rates of surface warming which were in better agreement with observed BTPs than the control simulation.

This strategy illustrates a possible probabilistic approach that allows to advance in the comparison of observed and synthetic BTPs in spite of the uncertainties related to the choice of a reference thermal state that accounts for the influence of pre-observational or pre-modeled climate. Such work may lay the way towards future applications in the context of detection/attribution studies. 


\subsection{A glimpse at the surface geothermal climate}

The comparisons of simulated and observed BTPs presented in the previous section aim at finding consistency between model simulations and past climate as registered in deep borehole temperature logs. Such assessment ultimately targets questions within the long term climate change context since only the lowest frequencies of GST are retained after being diffused into the ground.

A central aspect in the climatological interpretation of borehole profiles and also of time series of subsurface temperatures are the physical and biological mechanisms that may modulate the transfer of heat from the atmosphere to the upper layers of the soil. Therefore, a complementary view at the geothermal regime can be attained by considering the evolution of ground temperatures near the surface as represented by time series of soil temperature monitored at various levels, typically to a maximum depth of about $10 \mathrm{~m}$.

Climate reconstructions based on inversion of BTPs rely on two main assumptions which furnish the recovery of GST histories from BTPs and their legacy of SAT changes: i) changes in SAT are tightly coupled and translate well into GST changes; ii) the resulting changes in skin ground surface temperature propagate into the subsurface by thermal conduction. From this perspective it becomes important: $i$ ) to ascertain how atmospheric and surface conditions perturb the relation between SAT and GST; $i$ ) to verify that the propagation of surface temperature changes to the subsurface is dominated by heat conduction and to identify and understand potential situations that deviate from this basic assumption. Therefore, a large body of research has been devoted to understanding the processes modulating the generation and downward propagation of a climate signal at the ground surface. Some of those mechanisms, like snow cover and soil moisture changes, have been briefly discussed in Sect. 3; others involve vegetation and land use changes, evapotranspiration, precipitation, albedo, snow melting, etc. Most of the studies have a local focus which allows for the consideration of specific conditions, climatological types, seasons or soil types. Through a large variety of situations and case studies, the broad validity of the conductive regime and the coupling of air-ground temperatures at frequencies beyond the annual cycle is supported both by observational evidence (e.g. Putnam and Chapman, 1996; Beltrami, 2001a; Sokratov and Barry, 2002; Smerdon et al., 2003, 2004; Hu and Feng, 2005; Mottaghy and Rath, 2006; Chudinova et al., 2006; Smerdon et al., 2006; Demetrescu et al., 2007) and land surface model assessments (e.g. Lin et al., 2003; Stieglitz et al., 2003; Bartlett et al., 2004; Pollack et al., 2005; Stieglitz and Smerdon, 2007).

In turn, GCM modeling efforts are concerned with the degree of realism with which the surface thermal regime is reproduced since soil temperatures and with a broader perspective, soil moisture and other hydrological variables, are relevant parameters in air ground interaction. As discussed in
Sect. 3 the soil thermal and hydrological states are shaped by surface conditions (surface temperature, precipitation, snow cover, vegetation, land use, etc., Lewis and Wang, 1998; Hu and Feng, 2003; Zhang, 2005; Zhang et al., 2005; Davin et al., 2007). However, the thermal and hydrological conditions in the subsurface have also the potential to influence surface climate by modulating turbulent latent and sensible heat fluxes (e. g. Peters-Lidard et al., 1998; Sokratov and Barry, 2002; Schaefer et al., 2007) that feed back to regional climate (e.g. Bhatta et al., 2003; Kueppers et al., 2007; Taylor et al., 2007). In addition, the exchange of matter fluxes (e.g., $\mathrm{CO}_{2}, \mathrm{CH}_{4}$ ) regulated by soil temperatures and moisture plays a critical role in global climate through the dynamics of biogeochemical cycles (e.g. Risk et al., 2002a,b; Kellman et al., 2007; Riveros-Iregui et al., 2007).

Therefore, a realistic simulation of air-ground interactions is crucial to obtain a credible representation of the energy balance at the surface and related climate feedbacks on temperature, precipitation, evapotranspiration, convection, regional atmospheric circulation, etc. (e.g. Walker and Rowntree, 1977; Dirmeyer, 2000; Zhu and Liang, 2005; Seneviratne et al., 2006; Davin et al., 2007; Fischer et al., 2007b; Miguez-Macho et al., 2005, 2007).

The work of Zhu and Liang (2005) constitutes an interesting contribution that illustrates the performance of GCM and regional climate models (RCMs) in reproducing soil temperatures. This work uses the climate version of the PSU-NCAR Mesoscale Model MM5 (CMM5, Liang et al., 2001) driven by NCEP-DOE AMIP II reanalysis (R2, Kanamitsu et al., 2002) during the 1982-2002 period to produce a dynamical downscaling over Central North America. Both the outputs of the R 2 and the CMM 5 are compared to $0.1 \mathrm{~m}$ and $1.0 \mathrm{~m}$ deep soil temperatures from the $\mathrm{Hu}$ and Feng (2003) dataset over the contiguous US. Overall, the spatial variability, annual cycles and interannual variability simulated by the R 2 and CMM 5 capture realistically the details of soil temperature variability. However some systematic cold biases in the simulated soil temperatures are found for reasons still unknown. The higher resolution CMM 5 simulation produces more realistic regional details and overall smaller biases than the driving R 2 GCM reanalysis output, thus supporting the added value of the dynamical downscaling. Stendel et al. (2007) arrive at a similar result in an exercise where a mapped climatology of ground temperatures over Yakutia (Eastern Siberia) is compared with those simulated by a permafrost model driven by the GCM (ECHAM4OPYC3) and by a RCM (HIRHAM, with boundary conditions provided by ECHAM4-OPYC3).

The coarse resolution of GCMs and their relatively simple parameterizations (von Storch, 1995) hamper an accurate representation of specific soil thermal regimes as in the case of permafrost. At high latitudes, permafrost soils and the variability through thawing and freezing of the depth of the active layer are primary components of the land-atmosphere system and have been the target of a large number of sim- 
ulation efforts. This interest is justified by the sensitivity of permafrost to climate change (see Sect. 5). Since the horizontal resolution of GCMs is coarse, their soil model components produce, if at all, very poor simulations of permafrost dynamics. In general, two types of downscaling approaches are adopted. One is the use an off-line soil model forced with boundary conditions provided by either a GCM (e.g. Stendel and Christensen, 2002; Sazonova and Romanovsky, 2004), reanalysis data (Malevsky-Malevich et al., 2001; Nicolsky et al., 2007), or observations (Zhang et al., 2005; Moelders and Romanovsky, 2006). The other is the use of a nested RCM with a more sophisticated land surface component (e.g. Sushama et al., 2007). An exception is the work of Stendel et al. (2007) where the ECHAM4-OPYC3 GCM is used to provide driving conditions for a RCM, the output of which is in turn used to specify boundary conditions for a sophisticated permafrost model on the same grid as the GCM.

The wealth of studies in this branch of research is considerable and deserves attention by itself in its applications both to current and future climate. However, few pieces of work actually comment on the performance of the forcing climate models to simulate soil temperatures. This is due to the general inability of the forcing GCMs to reproduce permafrost and to the fact that this task is ultimately accomplished by the off-line land surface model or the nested regional model; also, often other permafrost related variables are diagnosed and compared to observations for validation like the thickness of the active later, permafrost area, freezing and thawing indices, snow cover, etc. (Malevsky-Malevich et al., 2001; Sazonova and Romanovsky, 2004). Some interesting case studies exist though that describe comparisons of simulated and observed soil temperatures in the process of their validation assessments. For instance Malevsky-Malevich et al. (2001) report on a fairly good agreement between observed soil temperature at $15 \mathrm{~m}$ depth over Siberian permafrost and that simulated by their land surface model driven by reanalysis data (Kalnay et al, 1996). Sushama et al. (2006) provide an example in which they validate the performance of current climate simulations with the Canadian Regional Climate Model (CRCM) with ca. $45 \mathrm{~km}$ horizontal resolution driven by the Canadian Coupled General Circulation Model (CGCM2) by comparing simulated and observed $20 \mathrm{~m}$ deep temperature profiles at three locations. They report cold temperature biases in the upper subsurface in winter and spring and warm biases in summer and autumn, with the annual contributions balancing out and presenting reasonable agreement at the deeper layers of the simulated and observed boreholes.

In the remaining part of this section this text will focus on the broad aspects that characterize the conductive regime in the upper $10 \mathrm{~m}$ of the soil as simulated by the 5-layer soil submodel embedded in the ECHO-G model. This will help both the purpose of providing a qualitative description of the realism of the model in non-permafrost areas and at the same time to introduce the problem of the boundary condition that is typically prescribed at the bottom of the soil sub-model in GCMs.

Figure 9 shows the evolution of daily temperatures at two locations representative of a positive and a negative SATGST difference in Fig. 1d. In one of them, air-ground coupling is strongly modulated by soil moisture whereas in the other the presence of snow cover is more important as discussed in Figs. 2 and 3. The grid-point selection is not fully arbitrary though since it is intended to serve for comparison with observational data described in Smerdon et al. (2003, 2004, 2006). Two model grid-points were selected close to Fargo (real coordinates: $46.9^{\circ} \mathrm{N} 96.8^{\circ} \mathrm{W}$; model coordinates: $46.39^{\circ} \mathrm{N} 96.5^{\circ} \mathrm{W}$ ) and Cape Hatteras (real: $35.25^{\circ} \mathrm{N}$ $75.54^{\circ} \mathrm{W}$; model: $35.26^{\circ} \mathrm{N} 78.75^{\circ} \mathrm{W}$ ). For both cases, the last 6 years in the FOR 2 model simulation are shown (FOR 1 delivers similar results). Fargo is a good example of a snow variability dominated site with SAT values which often range between $-30^{\circ} \mathrm{C}$ in winter and $30^{\circ} \mathrm{C}$ in summer (e.g. Smerdon et al., 2004). In the simulated years shown herein the range is slightly smaller, with minimum (maximum) values of $-25^{\circ} \mathrm{C}\left(25^{\circ} \mathrm{C}\right)$. The presence of snow prevents the cooling of the upper subsurface layers, so that the annual cycle is shifted with depth to above zero temperatures producing the typical negative SAT-GST offset (see Fig. 1): at $1.23 \mathrm{~m}$ below the ground temperatures rarely reach values below $-5^{\circ} \mathrm{C}$ and at $4.13 \mathrm{~m}$ they are always positive. Cape Hatteras is an example of a site where soil moisture is important since the largest deviations between SAT and GST arise due to latent heat exchanges during summer (not shown; see Smerdon et al., 2004). The SAT annual cycle typically ranges between $0^{\circ} \mathrm{C}$ and $30^{\circ} \mathrm{C}$ in the observations and $0^{\circ} \mathrm{C}$ and $25^{\circ} \mathrm{C}$ in the simulations. In this case there is no apparent shift with depth since the temperature series scarcely reaches negative values.

The annual cycle is further damped and phase shifted with depth due to the effects of conduction on the downward propagation of a harmonic temperature signal. This becomes apparent at both sites. For each harmonic component of the temperature variations at the surface with amplitude $A_{0}$, harmonic frequency $\omega$ and phase $\epsilon$ represented by $T(z=0, t)=A_{0} \cos (\omega t+\epsilon)$, the conductive propagation with depth of this signal is given (Carslaw and Jaeger, 1959) for depth $z$ and time $t$ by

$T(z, t)=A_{0} e^{-k z} \cos (\omega t+\epsilon-k z)$

where the $\mathrm{k}$ is $(\pi / \tau \kappa)^{\frac{1}{2}}, \tau$ being the harmonic period and $\kappa$ the thermal diffusivity. Thus, for each frequency component, the amplitude $(A)$ and phase shift $(\phi)$ change with depth according to:

$$
\begin{aligned}
\ln A & =\ln A_{0}-k z \\
\phi & =\epsilon-k z
\end{aligned}
$$

The amplitude decay and phase shift due to heat conduction is better illustrated in Fig. 10 by focusing exclusively on the 


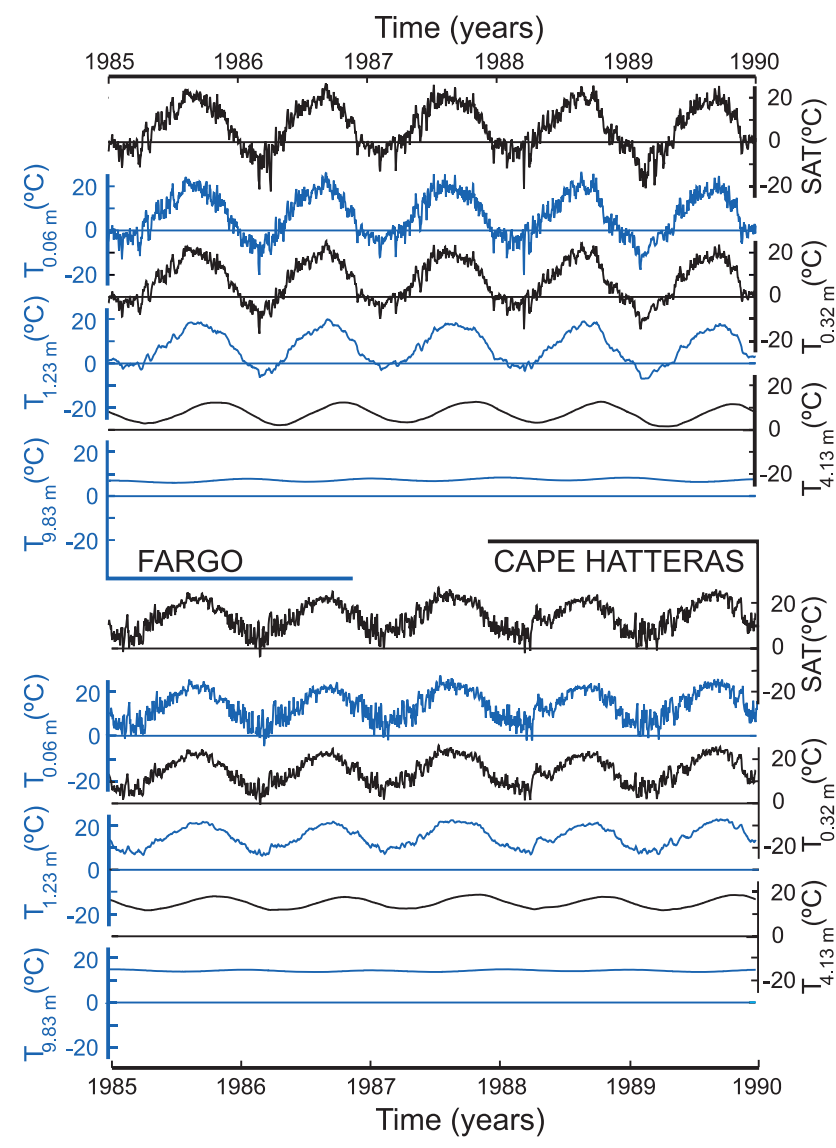

Fig. 9. SAT daily temperatures and soil temperatures at the various model depths in FOR 2 for two grid-points located close to Fargo (real coordinates: $46.9^{\circ} \mathrm{N} 96.8^{\circ} \mathrm{W}$; model coordinates: $46.39^{\circ} \mathrm{N}$ $96.5^{\circ} \mathrm{W}$ ) and Cape Hatteras (real: $35.25^{\circ} \mathrm{N} 75.54^{\circ} \mathrm{W}$; model: $35.26^{\circ} \mathrm{N} 78.75^{\circ} \mathrm{W}$ ). Time series show the last five years in the FOR 2 simulation.

annual cycle. A cosine wave of 12 month period has been fitted to the annual temperature evolution at each soil model level to determine the amplitude and relative phase of the wave. In order to consider a larger number of years and attain more robust estimates, the period 1960 to 1990 was used. The natural logarithm of the amplitude and the phase shift has been represented for the grid-points close to Fargo and Cape Hatteras over the complete width of each soil model layer (solid lines).

Also shown is the expected profile of a conductive regime using the model thermal diffusivity value for the grid-points close to Fargo and Cape Hatteras (dashed lines). The modeled range of surface temperature at Fargo is larger than at Cape Hatteras as in the observations (Smerdon et al., 2004). The average fitted amplitude of the SAT annual wave at Fargo is $13.9 \mathrm{~K}$ whereas a value of $17.8 \mathrm{~K}$ is found in observations; for Cape Hatteras the model simulation provides a value of $9.0 \mathrm{~K}$ whereas the observations indicate an amplitude of $8.6 \mathrm{~K}$.

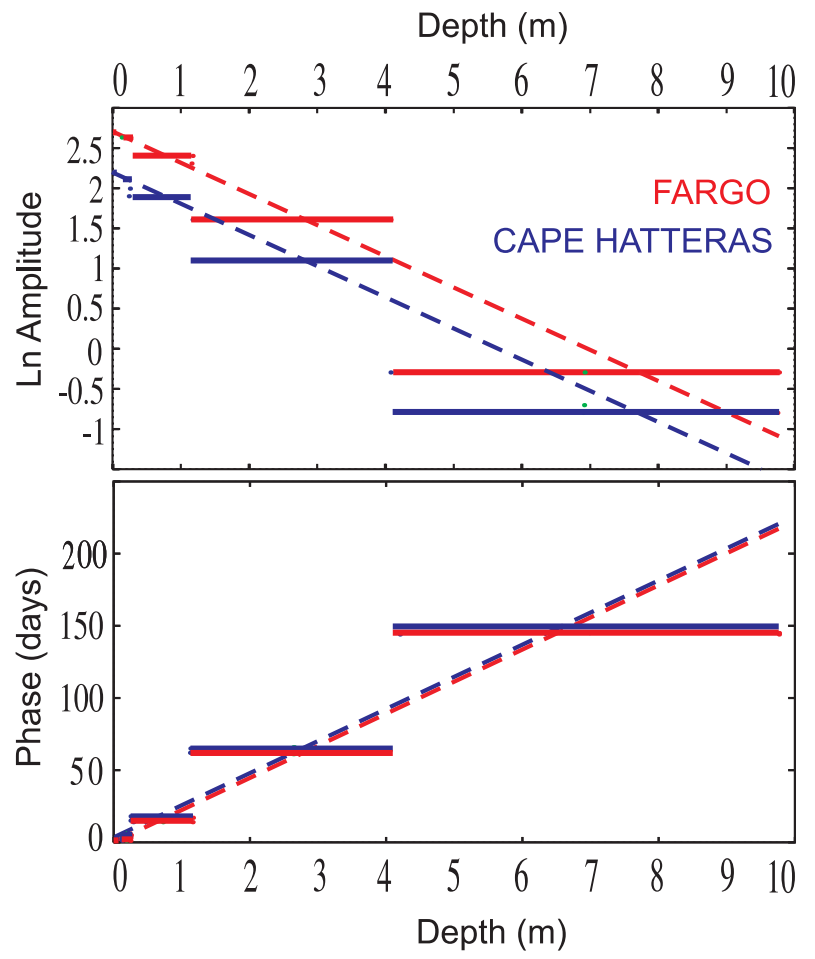

Fig. 10. Natural logarithm of the amplitude of the annual signal against depth at the grid-points in Fig. 9. Solid lines represent amplitude (top) and phase (bottom) over the complete width of each soil layer. Dashed lines depict the expected amplitude and phase changes with depth under conductive regime conditions

The slight over and under estimations in simulated amplitudes relative to reported observational values also translate into the subsurface temperatures. In the case of Fargo, the tendency to underestimate the amplitude of SAT annual range would be consistent with the underestimations reported in Zhu and Liang (2005) for the same area.

The vertical gradients of amplitude attenuation and phase shift are somewhat intermediate in the model simulations compared to the observed ones at Fargo and Cape Hatteras. This can be justified by the model thermal diffusivity $\left(\kappa=0.75 \times 10^{-6} \mathrm{~m}^{2} \mathrm{~s}^{-1}\right)$ which is larger than that deduced from observations at Fargo $\left(0.37 \times 10^{-6} \mathrm{~m}^{2} \mathrm{~s}^{-1}\right)$ and slightly smaller than that at Cape Hatteras $\left(1.04 \times 10^{-6} \mathrm{~m}^{2} \mathrm{~s}^{-1}\right)$. The evolution of phase shift with depth basically overlaps at both sites. Both changes in amplitude and phase for each soil model level follow quite closely the conductive regime.

However, for the lowest model layer slight differences from the conductive regime should be expected, because of the imposed boundary condition of zero flux at the bottom soil model level. Such deviations have been reported by Lynch-Stieglitz (1994) and Sun and Zhang (2004) for the annual cycle and extended to lower frequencies by Smerdon and Stieglitz (2006). The influence of a zero flux lower 
boundary condition on the subsurface propagating signals at a given depth depends on the frequency of the signal and the depth at which the boundary condition is imposed. Thus, the bottom boundary condition placement (BBCP) should be selected deep enough to avoid a significant perturbation of the subsurface thermodynamics, i.e. what can be called a causally detached BBCP. Lynch-Stieglitz (1994) studied the impact of a $2.3 \mathrm{~m}$ deep BBCP in the GISS model on the propagation of annual temperatures, which Sun and Zhang (2004) extended for various BBCP depths. Smerdon and Stieglitz (2006) assessed the impact of the BBCP on the propagation of harmonic signals of daily to millennial timescales using analytical solutions of the one-dimensional heat conduction equation. The results indicated that the appropriate BBCP is dependent on the time-scale of interest and this should be taken into consideration in soil models within GCMs. Given that typical depths for soil models in GCMs range between 3 and $10 \mathrm{~m}$, it is likely that significant deviations occur in the subsurface simulated thermal regime due to these shallow configurations. In the case of the ECHO-G model, the $\mathrm{BBCP}$ at $9.83 \mathrm{~m}$ is deep enough to produce only negligible perturbations on the annual wave. However, perturbations at lower frequencies cannot be ruled out.

The amplitude damping of frequencies shorter than the annual cycle is illustrated in Fig. 11 by showing a low pass filtered and extended version of the time series in Fig. 9. The annual cycle has been removed by subtracting from each monthly value the corresponding monthly long term average for the period 1960-1990. The series of anomalies for SAT and soil temperatures at each depth reveal now more clearly the low frequency variability. It is apparent that the high frequency variations in the layers closer to the surface are quickly damped and almost only decadal variability is present at the lowest model level. In the case of Fargo the large negative anomalies in SAT are visibly reduced to smaller changes in temperature at the first model layer, thus showing the effect of snow insulation. In the case of Cape Hatteras this effect is absent and the ground temperature anomalies of the upper layers overlay over those of SAT. A phase shift with depth for the envelope of the lowest frequencies is also observable at both sites.

The amplitude damping and phase shift for frequencies below the annual cycle can also be illustrated using spectral analysis. The amplitude of each component harmonic at the top and bottom layer can be obtained using a spectral analysis for which ordinates have been transformed to represent the amplitude of the wave at each frequency. The ratio of spectral amplitudes for the top and bottom time series is an estimation of the amplitude damping at each frequency. In addition, phase cross spectra can be used to picture the relative phase shift for the component harmonics between the top and the bottom layers. Figure 12 shows this analysis at the two selected grid-points together with the values that would be expected from the conductive regime (grey dashed lines) obtained from Eq. (3). The amplitude attenuation is in

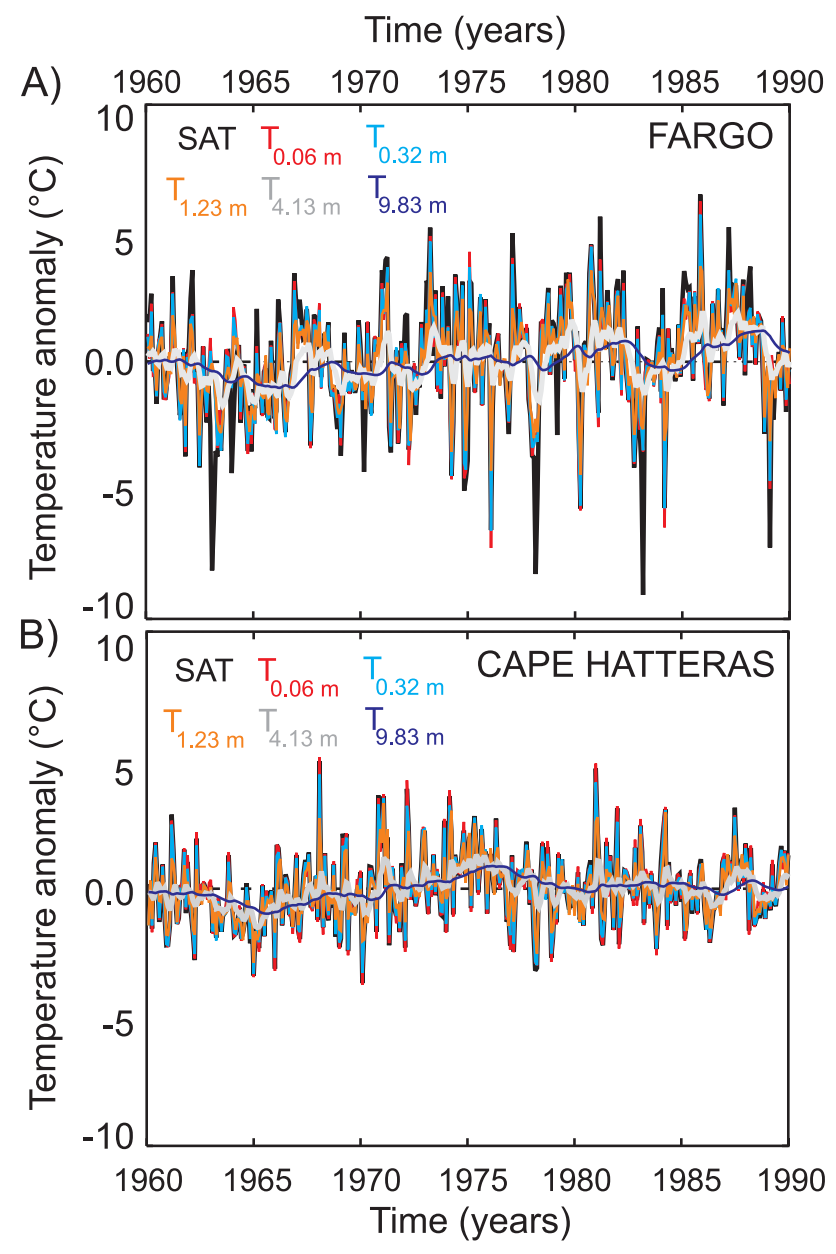

Fig. 11. Monthly SAT and GST anomalies with respect to the average annual cycle at the grid-points shown in Fig. 9 from the FOR 2 simulation. Each value represents the monthly differences between the absolute temperature value and the corresponding monthly average for the period 1960 to 1990.

good agreement with changes expected from the conductive regime with no zero flux condition for high and intermediate frequencies up to about $0.17 \mathrm{yr}^{-1}$ (ca. 6 years). Below that limit a gradual deviation from the pure conductive regime is observed. The phase shift is in good agreement with the conductive regime up to very low frequencies where some slight deviation is perceptible and zero phase shift is reached around $0.025 \mathrm{yr}^{-1}$. Thus, the low frequency time-scales are not attenuated as much as expected and become in phase after a certain threshold frequency. For instance, frequencies of $0.1 \mathrm{yr}^{-1}$, while phase shifted according to the theory, are only attenuated to $62 \%$ of their surface value when they should be reduced to about $42 \%$; frequencies around $0.05 \mathrm{yr}^{-1}$ get attenuated to about $90 \%$ of their value at the surface when they should be reduced to about $55 \%$ of it. This indicates that in Fig. 1d the filtered time series at various depths should present a gradual attenuation with depth rather than an almost parallel evolution. 
Frequency (1/year)

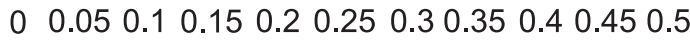

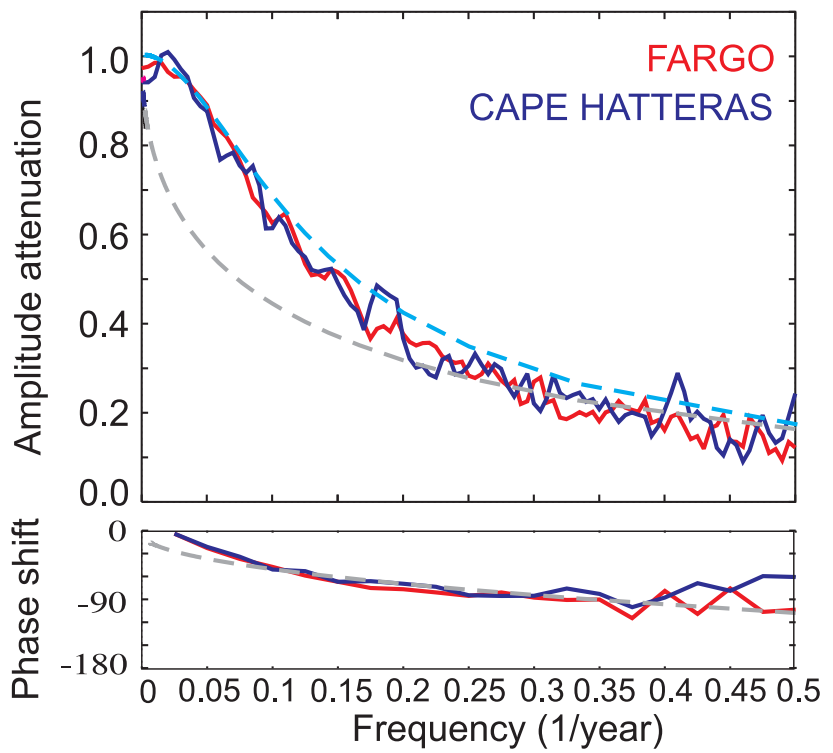

Fig. 12. (A) Ratio of spectral amplitude estimates for the temperature time series at the top and bottom model layers. Spectral estimates have been obtained from the time series of anomalies shown in Fig. 10. (B) Phase cross spectra for the top and bottom time series of temperature anomalies. Dashed grey lines indicate expected attenuation and phase shift according to heat conduction in a infinite half space with no bottom boundary flux condition; the blue dashed line depicts the expected amplitude attenuation using a BBCP as in the ECHO-G model.

The considerable deviations from the infinite half space conductive regime shown in the amplitude damping in Fig. 12 are due to the influence of the BBCP used in the model. This can be easily shown by considering that the amplitude attenuation produced in such an scenario is given by (e. g. Smerdon and Stieglitz, 2006):

$A / A_{0}=\left(\frac{\cosh [2(d-z) k]+\cos [2(d-z) k]}{\cosh [2 d k]+\cos [2 d k]}\right)^{1 / 2}$

where $d$ is the depth of the BBCP. Equation (4) can be valued for for each frequency thus obtaining the expected amplitude attenuation for the specific case of the ECHO-G model. This is shown with a blue dashed line in Fig. 12. For the phase shift a similar analysis can be performed (not shown here).

Thus, as shown by other authors with one dimensional head conduction models (Lynch-Stieglitz, 1994; Sun and Zhang, 2004; Smerdon and Stieglitz, 2006), the use of zero flux conditions and shallow soil models in GCMs can impact the simulation of temperature at low frequencies with a sensitivity that depends on the frequency of the signal, the value of the subsurface thermal properties and the BBCP. In addition to the temperature simulation, it can be argued that the use of shallow soil models impacts other variables like the simulated amount of heat stored into the subsurface. This can be particularly important in the context of simulations of future climate change.

\section{Some comments about estimations of future climate change}

Changes in future climate could be of relevance for the subsurface climate since changes in soil temperature and moisture could modify the air-ground coupling and all associated feedbacks. In particular permafrost areas are reported to be specially sensitive to climate change as warming could affect permafrost feedbacks to climate and produce other potential impacts on infrastructures, ecosystem changes, carbon storage, etc. (Cherkauer and Lettenmaier, 1999; Oechel et al., 2000; Nelson, 2003; Stieglitz et al., 2003). Therefore, it is not surprising that most efforts concerning the simulation of subsurface temperatures in climate change scenarios have been developed with a focus on permafrost regions.

Sushama et al. (2006) simulated present (1961-1990) and changes in future (2041-2070) soil temperatures over a domain covering northeastern Canada using a 1-D heat conduction model (Goodrich, 1982) driven by surface boundary conditions provided by skin surface temperatures and snow cover from transient climate change simulations with the Canadian Regional Climate Model (CRCM, Caya and Laprise, 1999) at a resolution of $45 \mathrm{~km}$, in turn, forced by the Canadian Coupled GCM (CCGCM2). Their results indicate future warming under the IPCC scenario IS92a (Leggett et al., 1992) in annual mean, maximal and minimal soil temperatures near the surface and a widening of the active layer above the permafrost by more than 50\%. In Sushama et al. (2007) they use an alternative approach by avoiding the use of the off-line soil model and implementing a dynamical downscaling using an improved version of the CRCM that incorporates sophisticated land surface model (CLASS Verseghy et al., 1993). They indicate increases of 4 to $6^{\circ} \mathrm{C}$ for the period 2041-2070 relative to 1961-1990 under climate change scenario A 2 with implications also for soil hydrology.

Though some discussion still exists (Delisle, 2007) comparable results have been recently reported for various permafrost areas which add up to a wealth of existing research (see Anisimov and Nelson, 1996, 1997; Malevsky-Malevich et al., 2001; Nelson and Anisimov, 1993; Lawrence and Slater, 2005, and references therein): for instance Sazonova and Romanovsky (2004) use boundary conditions from climate change simulations with six GCMs and estimate for the East Siberian transect increases in the thickness of the active layer of 0.5 to $2 \mathrm{~m}$ on average as well as temperature increments of 2 to $6^{\circ}$ by the end of the 21st century; Stendel et al. (2007) coincide on their results when analysing outputs of the GIPL permafrost model driven by boundary condi- 
tions provided in a donwscaling exercise for Eastern Siberia using the HIRHAM RCM driven by the ECHAM4-OPYC3 GCM outputs in the A2 and B2 scenarios; Cheng and $\mathrm{Wu}$ (2007) estimate future permafrost sinking for the QinghaiTibet Plateau by the end of the century. Also, using a climate change detection approach, Isaksen et al. (2007) report extreme near-surface permafrost warming in 2005-2006 in Svalbard that is found to be compatible with estimated warming scenarios for the late 21 st Century.

A detailed account of the results of studies assessing permafrost sensitivity to climate change with current climate and land-surface models is beyond the scope of this paper. Achievements in this area of research have brought to the forefront the necessity of a more realistic simulation of the subsurface climate to adequately reproduce air-ground interaction; this being also valid for non-permafrost areas (e.g. Liang et al., 2001; Seneviratne et al., 2006). In addition, a complementary perspective that addresses the importance of an improved representation of subsurface climate in GCMs is also pertinent since it could have implications not only in the simulation of regional to large scale soil regimes like in the case of permafrost but also in climate at hemispherical to global scales through changes in the energy balance at the surface.

GCMs and RCMs incorporate relatively shallow (between 3 and $10 \mathrm{~m}$ deep) soil models with a flux condition (typically zero flux) at the bottom boundary (see Sect. 4.2). Since such $\mathrm{BBCP}$ affects the simulation of subsurface temperatures near the surface (Smerdon and Stieglitz, 2006), it can be argued that the surface could be possibly influenced by this artificial BBCP, for instance by changes in surface heat fluxes, variations in the permafrost, hydrology, ground-air coupling, etc. Improved land-air interactions have proven to have a strong impact in the simulation of future climate (e.g. Seneviratne et al., 2006; Fischer et al., 2007a); the question arises whether a more realistic representation of the underground thermal regime can have potential impacts on surface climate. One source of influence could be the heat storage capacity of the ground. The shallow soil model configurations can potentially underestimate the heat storage capacity of the ground and concentrate the simulated warmth near the surface instead of diffusing it into the deep ground.

This additional energy which is not stored into the ground can be compared to a change in external forcing in as much as it represents a surplus of energy that is misplaced into other parts of the climate system. It can be argued that as an additional amount of energy it would potentially contribute to warming in the global energy balance (Stevens et al., 2007).

If that were the case, part of the energy which in reality should be stored into a realistically deep subsurface would be available, in the model, for other parts of the climate system and potentially produce a warmer climate at the surface. The capacity of the subsurface to store heat as a function of BBCP was specifically revised by Stevens et al. (2007) who forced a land surface model (Goodrich, 1982) with SAT provided by the ECHO-G simulations presented herein. One of the simulations, FOR1, was continued to 2100 under IPCC A 2 and B 2 scenarios (Zorita et al., 2005) which allowed for an assessment of the amount of heat stored into the soil under future climate change conditions. This assessment was done by initializing an off-line land surface model with a configuration of $1000 \mathrm{~m}$ depth with the simulated temperatures during the period 1000 to 1990 . After that, several sensitivity experiments were produced by driving the land surface model from the initial conditions attained at year 1990 with the temperature changes simulated under the A 2 and B 2 scenarios. This was done for different configurations in which the BBCP was imposed at depths between 1 and $1000 \mathrm{~m}$. Results suggested that shallow BBCPs $(10 \mathrm{~m})$ could reduce the capacity of the continental subsurface to store heat by about $1.0 \times 10^{23} \mathrm{~J}$ during an A 2 scenario run. Deepening the BBCP to about $120 \mathrm{~m}$ increased the heat storage capacity by about 5 times. This increment is more than an order of magnitude greater than the heat absorbed by both the whole atmosphere and the continents in the second half of the 20th century (Beltrami et al., 2002, 2006a; Levitus et al., 2005; Huang, 2006a,b).

Figure 13 shows the heat gained by the ECHO-G soil model in the simulations used in Stevens et al. (2007). The spatial distribution of total heat stored into the ground at the end of the simulations is shown in Fig. 13b. In 2100 $1.3 \times 10^{8} \mathrm{~J}\left(0.8 \times 10^{8} \mathrm{~J}\right)$ are gained by the $9.83 \mathrm{~m}$ deep subsurface in the A 2 (B 2) scenario. These quantities are comparable to those calculated in Stevens et al. (2007) by forcing the land surface model using a depth of $10 \mathrm{~m}$ with FOR $1 \mathrm{NH}$ SAT temperatures. If a $150 \mathrm{~m}$ deep soil model would be able to store as much as 5 times the original quantity this would mean that about $6.5 \times 10^{8} \mathrm{~J}$ would be gained if a more realistic subsurface was used. This quantity is considerably larger than the actual difference of heat accumulated within the A 2 and $\mathrm{B} 2$ scenarios: $0.5 \times 10^{8} \mathrm{~J}$. This suggests that changing to a more realistic (deeper) subsurface could have a larger impact on heat storage and on the related energy balance than using a different forcing scenario. This result has been recently further developed and geographycally extended and illustrated in MacDougall et al. (2008).

\section{Conclusions}

The last years have witnessed a growth of reconstruction and model simulation studies targeting an improved understanding of climate variability during the last millennium. Both types of approaches offer multiple possibilities of potential interaction that can contribute to our knowledge of past climate through comparison and validation of various aspects of reconstructions and simulations. These efforts can also have implications within the context of future climate change assessment, after all a major motivation for paleoclimate research. 


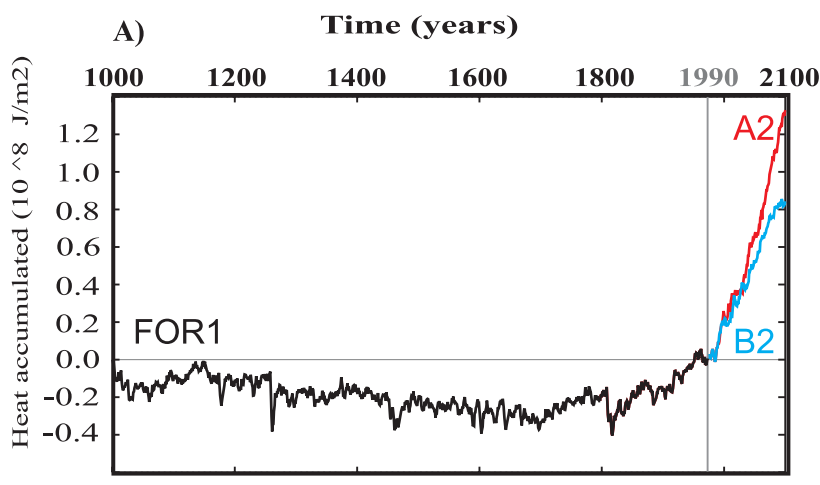

B) Heat accumulated $2100 \mathrm{AD}\left(10 \wedge 8 \mathrm{~J} / \mathrm{m}^{\wedge} 2\right)$

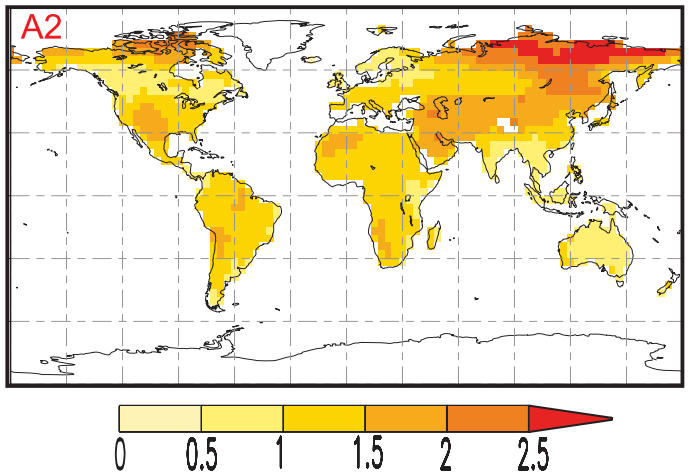

Fig. 13. (A) Cumulative amount of heat gained by the subsurface FOR 1 simulation (1900-1990) and continued under IPCC scenarios A 2 and B 2 (1991-2100). (B) Spatial distribution of the total amount of heat stored into the ground at 2100 in the A 2 scenario.

Borehole climatology has significantly contributed to this context by recovering information of past multi-centennial surface temperature trends from the thermal signature imparted in subsurface rocks. This text has reported about and discussed recent steps and ideas that stem from the interaction of this discipline with climate model exercises.

We have focused mostly on continental boreholes allowing very limited or no attention to other subsurface types for which a more extensive treatment would be desirable. One of them is permafrost which receives partial attention in Sects. 4.2 and 5. In addition, there are also important pieces of work which tell interesting lessons about boreholes measured in ice cap areas. These boreholes deliver longer temperature reconstructions and some interesting attempts have been made to understand their thermodynamics with the aid of GCMs (Dahl-Jensen et al., 1998; Jouzel, 1999; Krinner et al., 1997; Werner et al., 2000)

The use of GCMs as a test bed for climate reconstruction methods has provided evidence for the robustness of the borehole approach in delivering a consistent picture of low frequency climate variability under various methodological issues. In particular, trends in simulated snow cover and soil moisture do not seem to hamper the ability of inversion models to retrieve the past temperature evolution; the same seems to be the case with regard to the potential influence of experimental aspects like the distribution of logging dates and depth. Results suggest that there could be an interesting issue in the effects of noise, which, in extreme cases, could lead to an under-estimation rather than an overestimation of past climate variability as it has been suggested in the literature. Future efforts could consider a more realistic involvement of noise, both in borehole profiles and also with a regional perspective incorporating non-climate perturbations like horizontal heat advection, changes in vegetation, etc. The effect of multi-centennial changes in land surface cover has not been considered so far.

Comparison of observed and synthetic BTPs has given its first steps. Results point out a sensitivity of the temperature signature in BTPs to trends in external forcing and that there might be some regional coherence between observed and simulated BTPs which deserves further exploration. A relevant issue that stems from this line of work is that uncertainties in the generation of synthetic BTPs lead to the necessity of developing comparison strategies in a probabilistic framework. An additional issue which is lacking in this context is the incorporation of arguments that involve the effects of past glacial-interglacial changes.

Assessments of the realism of models in reproducing the subsurface geothermal regime evidence the need for more sophisticated soil models that help to better reproduce features of the air-ground interaction. This has been shown to be of particular importance in the simulation of permafrost regimes in which local and regional detail is achieved either with nested RCMs or with off-line land surface models. The performance of GCMs in reproducing the basics of heat conduction is hampered by the placement of a zero flux bottom boundary condition in the relatively shallow soil model components. Results of different assessments point out the necessity of incorporating soil components with causally detached bottom boundary conditions either by changing the nature of the bottom boundary condition itself and allowing for the dissipation of heat at this end or preferably through increasing the depth of the soil model component. A further aspect of relevance concerning the depth of soil models within GCMs is the capacity of heat storage which increases with depth and may significantly influence the energy balance at the surface in simulations of future climate change scenarios. This last issue constitutes a distinct example of how studies at the interface of proxy reconstructions and model simulations can provide potentially useful information to improve future climate change scenario simulations or at least to understand better the uncertainties associated with them.

Acknowledgements. This research was supported: in Spain by project SPECT (CGL2005-06097/CLI) and the Ramón y Cajal Program of the Ministerio de Educación y Ciencia (MEC) and project PalMA (CCG07-UCM/ESP-3045) by the Comunidad Autónoma de Madrid and the Universidad Complutense de Madrid; in Canada by the Natural Sciences and Engineering Research Council of Canada (NSERC), the Canadian Foundation for Climate and Atmospheric 
Sciences (CFCAS) and the Atlantic Innovation Fund (AIF-ACOACanada); and in Germany by the EU project Millennium European Climate. The authors thank Vladimir Cermák and two anonymous reviewers for their comments and suggestions. Also we appreciate the contributions from Volker Rath and Jason Smerdon, editors of this special volume.

Edited by: V. Rath

\section{References}

Ammann, C. M. and Wahl, E.: The importance of the geophysical context in statistical evaluations of climate reconstruction procedures, Climatic Change, 85, 71-88, 2007.

Ammann, C. M., Meehl, G. A., and Washington, W. M.: A monthly and latitudinally varying volcanic foricng dataset in simulations of the 20th century climate, Geophys. Res. Lett., 30(12), 1657, doi:10.1029/2003GL016875, 2003.

Ammann, C. M., Joos, F., Schimel, D. S., Otto-Bliesner, B. L., and Tomas, R. A.: Solar influence on climate during the past millennium: Results from transient simulations with the NCAR Climate System Model, P. Natl. Acad. Sci. USA, 104, 3713-3718, 2007.

Anisimov, O. A. and Nelson, F. E.: Permafrost distribution in the Northern Hemisphere under scenarios of climate change, Global Planet. Change, 14, 59-72, 1996.

Anisimov, O. A. and Nelson, F. E.: Permafrost zonation and climate change in the Northern Hemisphere: results from transient general circulation models, Climatic Change, 35, 241-258, 1997.

Bard, E., Raisbeck, G., Yiou, F., and Jouzel, J.: Solar irradiance during the last 1200 years based on cosmogenic nuclides, Tellus B, 52, 985-992, 2000.

Bartlett, M. G., Chapman, D. S., and Harris, R. N.: Snow and the ground temperature record of climate change, J. Geophys. Res., 109, F04008, doi:10.1029/2004JF000224, 2004.

Bartlett, M. G., Chapman, D. S., and Harris, R. N.: Snow effect on North American ground temperatures, 1950-2002, J. Geophys. Res., 110, F03008, doi:10.1029/2005JF000293, 2005.

Battle, M., Bender, M., Sowers, T., Tans, P. P., Butler, J. H., Elkins, J. W., Ellis, J. T., Conway, T., Zhang, N., Lang, P., and Clarke, A. D.: Atmospheric gas cocentrations over the past century measured in air from firn and the South Pole, Nature, 383, 231-235, 1996.

Bauer, E. and Claussen, M.: Analyzing seasonal temperature trends in forced climate simulations of the past millennium, Geophys. Res. Lett., 33, L02702, doi:10.1029/2005GL024593, 2006.

Bauer, E., Claussen, M., Brovkin, V., and Huenerbein, A.: Assessing climate forcings of the earth system for the past millenium, Geophys. Res. Lett., 30(6), 1276, doi:10.1029/2002GL016639, 2003.

Beck, A. E., Shen, P. Y., Beltrami, H., Mareschal, J. C., Šafanda, J., Sebagenzi, M. N., Vasseur, G., and Wang, K.:

A comparison of five different analyses in the interpretation of five borehole temperature data sets, Palaeogeogr. Palaeocl. (Global Planet. Change Sect.), 98, 101-112, 1992.

Beltrami, H.: Energy balance of the Earth's surface: heat flux history in Eastern Canada, Geophys. Res. Lett., 27, 3385-3388, 2000 .
Beltrami, H.: On the relationship between ground temperature histories and meteorological records: a report on the Pomquet station., Global Planet. Change, 29, 327-348, 2001 a.

Beltrami, H.: Surface heat flux histories from inversion of geothermal data: energy balance at the Earth's surface, J. Geophys. Res., 106, 21 979-21 993, 2001b.

Beltrami, H.: Earth's long term memory, Science, 297, 206-207, 2002a.

Beltrami, H.: Climate from borehole data: energy fluxes and temperatures since 1500, Geophys. Res. Lett., 29(23), 2111, doi:10.1029/2002GL015702, 2002b.

Beltrami, H. and Bourlon, E.: Ground warming patterns in the Northern Hemisphere during the last five centuries, Earth Planet. Sci. Lett., 227, 169-177, 2004.

Beltrami, H. and Mareschal, J. C.: Resolution of ground temperature histories inverted from borehole temperature data, Global Planet. Change, 11, 57-70, 1995.

Beltrami, H., Jessop, A. M., and Mareschal, J. C.: Ground temperature histories in eastern and central Canada from geothermal measurements: evidence of climate change, Palaeogeogr Palaeocl. (Global Planet. Change Sect.), 98, 167-184, 1992.

Beltrami, H., Cheng, L., and Mareschal, J. C.: Simultaneous inversion of borehole temperature data for determination of ground surface temperature history, Geophys. J. Int., 129, 311-318, 1997.

Beltrami, H., Smerdon, J. E., Pollack, H., and Huang, S.: Continental heat gain in the global climate system, Geophys. Res. Lett., 29(8), 1167, doi:10.1029/2001GL014310, 2002.

Beltrami, H., Gosselin, C., and Mareschal, J. C.: Ground surface temperatures in Canada: spatial and temporall variability, Geophys. Res. Lett., 30(10), 1499, doi:10.1029/2003GL017144, 2003.

Beltrami, H., Ferguson, G., and Harris, R. N.: Long-term tracking of climate change by underground temperatures, Geophys. Res. Lett., 32, L19707, doi:10.1029/2005GL023714, 2005.

Beltrami, H., Bourlon, E., Kellman, L., and González-Rouco, J. F.: Spatial patterns of ground heat gain in the Northern Hemisphere, Geophys. Res. Lett., 33, L06717, doi:10.1029/2006GL025676, 2006a.

Beltrami, H., González-Rouco, J. F., and Stevens, M. B.: Subsurface temperatures during the last millennium: Model and Observation, Geophys. Res. Lett., 33, L09705, doi:10.1029/2006GL026050, 2006b.

Bense, V. and Beltrami, H.: The impact of horizontal groundwater flow and localized deforestation on the development of shallow temperature anomalies, J. Geophys. Res., 112, F04015, doi:10.1029/2006JF000703, 2007.

Bense, V. and Kooi, H.: Temporal and spatial variations of shallow subsurface temperature as a record of lateral variations in groundwater flow, J. Geophys. Res., 109, B04103, doi:10.1029/2003JB002782, 2004.

Bhatta, U. S., Schneider, E. K., and Dewitt, D. G.: Influence of North American land processes on North Atlantic Ocean variability, Global Planet. Change, 37, 33-56, 2003.

Blackwell, D. D., Steele, J. L., and Brott, C. A.: The terrain effect on terrestrial heat flow, J. Geophys. Res., 85, 4757-4772, 1980.

Bodri, L. and Cermak, V.: Borehole climatology: a new method how to reconstruct climate, Elsevier Science and Technology, Netherlands, 3rd edn., 2007. 
Bonan, G. B., Pollard, D., and Thompson, S. L.: Effects of boreal forest vegetation on global climate, Nature, 359, 716-718, 1992.

Bradley, R. S., Hughes, M. K., and Diaz, H. F.: Climate in Medieval Time. Science, 302, 404-405, 2003.

Bradley, R. S., Briffa, K. R., Cole, J., Hughes, M. K., and Osborn, T. J.: The climate of the last millennium: Paleoclimate, global change and the future, edited by: Alverson, K. D., Bradley, R. S., and Pedersen, T. F., Springer Verlag, Berlin, 105-141, 2003.

Briffa, K. R. and Osborn, T. J.: Blowing hot and cold, Science, 292, 662-667, 2002.

Briffa, K. R., Schweingruber, F. H., Jones, P. D., Osborn, T. J., Shiyatov, S. G., and Vaganov, E. A.: Reduced sensitivity of recent tree-growth to temperature at high northern latitudes, Nature, 391, 678-682, 1998.

Brown, R. D.: Northern Hemisphere snow cover variability and change, 1915-1997, J. Climate, 13, 2339-2355, 2000.

Brown, R. D. and Goodison, B. E.: Interannual variability in reconstructed Canadian snow cover, 1915-1992, J. Climate, 9, 12991318, 1996.

Brown, R. D., Brasnett, B., and Robinson, D.: Gridded North American Monthly Snow Depth and Snow Water Equivalent for GCM Evaluation, Atmos. Ocean, 41(1), 1-14, 2003.

Büntgen, U., Frank, D. C., Nievergelt, D., and Esper, J.: Summer temperature variations in the European Alps, AD 755-2004, J. Climate, 19, 5606-5623, 2006.

Bürger, G. and Cubasch, U.: Are multiproxy climate reconstructions robust?, Geophys. Res. Lett., 32, L23711, doi:10.1029/2005GL024155, 2005.

Bürger, G., Fast, I., and Cubasch, U.: Climate reconstruction by regression - 32 variations on a theme, Tellus A, 58, 227-235, 2006.

Cane, M. A., Braconnot, P., Clement, A., Gildor, H., Joussaume, S., Kageyama, M., Khodri, M., Paillard, D., Tett, S., and Zorita, E.: Progress in paleoclimate modeling, J. Climate, 19, 5031-5057, 2006.

Carslaw, H. S. and Jaeger, J. C.: Conduction of heat in solids, Oxford Univ. Press, New York, 2nd edn., 510 pp., 1959.

Caya, D. and Laprise, R.: A semi-implicit semi-Lagrangian regional climate model: the canadian RCM, Mon. Weather Rev., 127, 341-362, 1999.

Cermak, V.: Underground temperature and inferred climatic temperature for the past millennium, Palaeogeogr Palaeocl. (Global Planet. Change Sect.), 10, 1-19, 1971.

Chapman, D. S., Bartlett, M. G., and Harris, R. N.: Comment on "Ground vs. surface air temperature trends: implications for borehole surface temperature reconstructions" by $\mathrm{M}$. E. Mann and G. Schmidt, Geophys. Res. Lett., 31, L07205, doi:10.1029/2003GL019054, 2004.

Cheng, G. and Wu, T.: Responses of permafrost to climate change and their environmental significance, Qinghai-Tibet Plateau, Geophys. Res. Lett., 112, F02S03, doi:10.1029/2006JF000631, 2007.

Cherkauer, K. A. and Lettenmaier, D. P.: Hydrologic effects of frozen soils in the upper Mississippi river basin, J. Geophys. Res., 104, 19611-19621, 1999.

Chouinard, C. and Mareschal, J. C.: Selection of borehole temperature depth profiles for regional climate reconstructions, Clim. Past, 3, 297-313, 2007,

http://www.clim-past.net/3/297/2007/.
Chudinova, S. M., Frauenfeld, O. W., Barry, R. G., Zhang, T., and Sorokovikov, V. A.: Relationship between air and soil temperature trends and periodicities in the permafrost regions of Russia, J. Geophys. Res., 111, F02008, doi:10.1029/2005JF000342, 2006.

Clauser, C. and Mareschal, J. C.: Ground temperature history in central Europe from borehole temperature data, Geophys. J. Int., 121, 805-817, 1995.

Clow, G. D.: The extent of temporal smearing in surface temperature histories inferred from borehole temperature measurements. Palaeogeogr Palaeocl. (Global Planet. Change Sect.), 98, 81-86, 1992.

Cook, E. R.: Temperature histories from tree rings and corals, Clim. Dynam., 11, 211-222, 1995.

Cook, E. R., D’Arrigo, R. D., and Mann, M.: A well-verified, multyproxy reconstruction of the winter North Atlantic Oscillation Index since AD 1400, J. Climate, 15, 1754-1764, 2002.

Cooper, G. R. J. and Jones, M. Q. W.: Optimized inversion of borehole temperature data, Geophysics, 63, 331-336, 1998.

Correia, A. and Šafanda, J.: Ground surface temperature history at a single site in sourthern Portugal reconstructed from borehole temperatures, Global Planet. Change, 19, 155-165, 2001.

Crowley, T. J.: Causes of climate change over the past 1000 years, Science, 289, 270-277, 2000.

Cubasch, U., Voss, R., Hegerl, G. C., Waszkewitz, J., and Crowley, T. J.: Simulation of the influence of solar radiation variations on the global climate with an ocean-atmosphere general circulation model, Clim. Dynam., 13, 757-767, 1997.

Dahl-Jensen, D., Mosegaard, K., Gundestrup, N., Clow, G. D., Johnsen, S. J., Hansen, A. W., and Balling, N.: Past temperatures directly for the Greenland ice sheet, Science, 282, 268-271, 1998.

Davin, E. L., de Noblet-Ducoudré, N., and Friedlingstein, P.: Impact of land cover change on surface climate: Relevance of the radiative forcing concept, Geophys. Res. Lett., 34, L13702, doi:10.1029/2007GL029678, 2007.

Delisle, G.: Near-surface permafrost degradation: how severe during the 21st century?, Geophys. Res. Lett., 34, L09503, doi:10.1029/2007GL029323, 2007.

Demetrescu, C., Nitoiu, D., Boroneant, C., Marica, A., and Lucaschi, B.: Thermal signal propagation in soils in Romania: conductive and non-conductive processes, Clim. Past, 3, 637-645, 2007, http://www.clim-past.net/3/637/2007/.

Demezhko, D. Y.: Geothermal method for paleoclimate reconstruction (examples from the Urals, Russia), Yekaterinburg, UB RAS, 2001 (in Russian).

Demezhko, D. Yu. and Golovanova, I. V.: Climatic changes in the Urals over the past millennium an analysis of geothermal and meteorological data, Clim. Past, 3, 237-242, 2007, http://www.clim-past.net/3/237/2007/.

Déry, C. and Wood, E. F.: Analysis of snow in the 20th and 21st century Geophysical Fluid Dynamics Laboratory coupled climate model simulations, J. Geophys. Res., 111, D19113, doi:10.1029/2005JD006920, 2006.

Diaz, S. C., Touchan, R., and Swetnam, T. W.: A tree-ring reconstruction of past precipitation for Baja California Sur, Mexico, Int. J. Climatol., 21, 1007-1019, 2001. 
Dirmeyer, P. A.: Using a global soil wetness dataset to improve seasonal climate simulation, J. Climate, 13, 2900-2922, 2000.

Esper, J., Cook, E. R., and Schweingruber, F.: Low-frequency signals in long tree-ring chronologies for reconstructing past temperature variability, Science, 295, 2250-2253, 2002.

Etheridge, D., Steele, L. P., Langenfelds, R. L., Francey, R., Barnola, J., and Morgan, V.: Natural and anthropogenic changes in atmospheric $\mathrm{CO}_{2}$ over the last 1000 years from air in Antarctic ice and firn, J. Geophys. Res., 101, 4115-4128, 1996.

Etheridge, D. M., Steele, L. P., Francey, R. J., and Langenfelds, R. L.: Atmospheric methane between $1000 \mathrm{AD}$ and present: Evidence of anthropogenic emissions and climatic variability, J. Geophys. Res., 103, 15 979-15 993, 1998.

Ferguson, G., Beltrami, H., and Woodbury, A. D.: Perturbation of ground surface temperature reconstructions by groundwater flow?, Geophys. Res. Lett., 33, L13708, doi:10.1029/2006GL026634, 2006.

Fernández, J. and Cabal, J.: Heat-flow data and shallow thermal regime on Mallorca and Menorca (western Mediterranean), Tectonophysics, 203, 133-143, 1992.

Fischer, E. M., Luterbacher, J., Zorita, E., Tett, S. F. B., Casty, C., and Wanner, H.: European climate response to tropical volcanic eruptions over the last half millennium, Geophys. Res. Lett., 34, L05707, doi:10.1029/2006GL027992, 2007a.

Fischer, E. M., Seneviratne, S. I., Luethi, D., and Schär, C.: Contribution of land-atmosphere coupling to recent European summer heat waves, Geophys. Res. Lett., 34, L06707, doi:10.1029/2006GL029068, 2007b.

Foukal, P., North, G., and Wigley, T.: A stellar view on solar variations and climate, Science, 306, 68-69, 2004.

Frei, A., Robinson, D. A., and Hughes, M. G.: North American snow extent: 1900-1994, Int. J. Climatol., 19, 1517-1534, 1999.

Gao, C., Robock, A., and Ammann, C.: Volcanic forcing of climate over the past 1500 years: An improved ice core-based index for climate models, J. Geophys. Res., 113, D23111, doi:10.1029/2008JD010239, 2008.

Golovanova, I., Harris, R. N., Selezniova, G. V., and Stulc, P.: Evidence of climatic warming in the southern Urals region derived from borehole temperatures and meteorological data, Global Planet. Change., 29, 167-188, 2001.

González-Rouco, J. F., von Storch, H., and Zorita, E.: Deep soil temperature as proxy for surface air-temperature in a coupled model simulation of the last thousand years, Geophys. Res. Lett., 30, 2116-2119, 2003a.

González-Rouco, J. F., Zorita, E., Cubasch, U., von Storch, H., Fisher-Bruns, I., Valero, F., Montavez, J. P., Schlese, U., and Legutke, S.: Simulating the climate since 1000 AD with the AOGCM ECHO-G, ESA, SP 535, 329-338, 2003 b.

González-Rouco, J. F., Beltrami, H., Zorita, E., and von Storch, H.: Simulation and inversion of borehole temperature profiles in surrogate climates: Spatial distribution and surface coupling, Geophys. Res. Lett., 33, L01703, doi:10.1029/2005GL024693, 2006.

Goodrich, L. E.: The influence of snow cover on the ground thermal regime, Can. Geotech. J., 19, 421-432, 1982.

Goosse, H., Crowley, T. J., Zorita, E., Ammann, C. M., Renssen, H., and Driesschaert, E.: Modelling the climate of the last millennium: what causes the differences between simulations?, Geophys. Res. Lett., 32, L06710, doi:10.29/2005GL22368, 2005.
Goosse, H., Arzel, O., Luterbacher, J., Mann, M. E., Renssen, H., Riedwyl, N., Timmermann, A., Xoplaki, E., and Wanner, H.: The origin of the European "Medieval Warm Period", Clim. Past, 2, 99-113, 2006, http://www.clim-past.net/2/99/2006/.

Gosnold, C., Todhunter, P. E., and Schmidt, W.: The borehole temperature record of climate warming in the mid-continent of North America, Global Planet. Change, 15, 33-45, 1997.

Gosselin, C. and Mareschal, J. C.: Variations in ground surface temperature histories in the Thompson Belt, Manitoba, Canada: environment and climate changes, Global Planet. Change, 39, $271-$ 284, 2003.

Goto, S., Kim, H. C., Uchida, Y., and Okubo, Y.: Reconstruction of the ground surface temperature history from the borehole temperature data in the southeastern part of the Republic of Korea, J. Geophys. Eng., 2, 312-319, 2005.

Gouirand, I., Moberg, A., and Zorita, E.: Climate variability in Scandinavia for the past millennium simulated by an atmosphere-ocean general circulation model, Tellus A, 59, 30 49, $2007 \mathrm{a}$.

Gouirand, I., Moron, V., and Zorita, E.: Teleconnections between ENSO and North Atlantic in an ECHO-G simulation of the 1000-1990 period, Geophys. Res. Lett., 34, L06705, doi:10.1029/2006GL028852, 2007b.

Graham, N. E., Hughes, M. K., Ammann, C. M., Cobb, K. M., Oerling, M. P., Kennett, D. J., Kennett, J. P., Rein, B., Stott, L., Wigand, P. E., and Xu, T.: Tropical Pacific midlatitude teleconnections in medieval times, Clim. Change, 83, 241-285, 2007.

Guiot, J., Nicault, A., Rathgeber, C., Edouard, J., Guibal, F., Pichard, G., and Till, C.: Last-millennium summer-temperature variations in western Europe based on proxy data, Holocene, 15, 489-500, 2005.

Haigh, J. D.: Modelling the impact of solar variability on climate, J. Atmos. Sol.-Terr. Phy., 61, 63-72, 1999.

Hamza, V. M., Cavalcanti, A. S. B., and Benyosef, L. C. C.: Surface thermal perturbations of the recent past at low latitudes inferences based on borehole temperature data from Eastern Brazil, Clim. Past, 3, 513-526, 2007, http://www.clim-past.net/3/513/2007/.

Hansen, J., Nazarenko, L., Ruedy, R., Sato, M., Willis, J., del Genio, A., Koch, D., Lacis, A., Lo, K., Menon, S., Novakov, T., Perlwitz, J., Russell, G., Schmidt, G. A., and Tausnev, N.: Earth's energy imbalance: confirmation and implications, Science, 308, 1431-1435, 2005.

Harris, R. N.: Variations in air and ground temperature and the POM-SAT model: results from the Northern Hemisphere, Clim. Past, 3, 611-621, 2007, http://www.clim-past.net/3/611/2007/.

Harris, R. N. and Chapman, D. S.: Climate change in the Colorado Plateau of eastern Utah inferred from borehole temperatures, J. Geophys. Res., 100, 6367-6381, 1995.

Harris, R. N. and Chapman, D. S.: Mid-Latitude $\left(30^{\circ}-60^{\circ} \mathrm{N}\right)$ climatic warming inferred by combining borehole temperatures with surface air temperatures, Geophys. Res. Lett., 28, 747-750, 2001.

Harris, R. N. and Gosnold, W. D.: Comparisons of borehole temperature depth profiles and surface air temperatures in the northern plains of the USA, Geophys. J. Int., 138, 541-548, 1999.

Hartmann, A. and Rath, V.: Uncertainties and shortcomings of 
ground surface temperature histories derived from inversion of temperature logs, J. Geophys. Eng., 2, 299-311, 2005.

Hegerl, G. C., Crowley, T. J., Baum, S. K., Kim, K. Y., and Hyde, W. T.: Detection of volcanic, solar and greenhouse gas signals in paleo-reconstructions of Northern Hemispheric temperature, Geophys. Res. Lett., 30(5), 1242, doi:10.1029/2002GL016635, 2003.

Hegerl, G. C., Crowley, T. J., Hyde, W. T., and Frame, D. J.: Climate sensitivity constrained by temperature reconstrcutions over the past seven centuries, Nature, 440, 1029-1032, 2006.

Hegerl, G. C., Crowley, T. J., Allen, M., Hyde, W. T., Pollack, H. N., and Zorita, J. S. E.: Detection of human influence ona a new, validated 1500 year temperature reconstruction, J. Climate, 20, 650-666, 2007a.

Hegerl, G. C., Zwiers, F. W., Braconnot, P., Gillett, N. P., Luo, Y., Orsini, J. A. M., Nicholls, N., Penner, J. E., and Stott, P. A.: Understanding and attributing climate change: Climate Change 2007: The Physical Science Basis, in: Contribution of Working Group I to the Fourth Assessment Report of the Intergovernmental Panel on Climate Change, edited by: Solomon, S., Qin, D., Manning, M., Chen, Z., Marquis, M., Averyt, K. B., Tignor, M., and Miller, H. L., Cambridge University Press, Cambridge, United Kingdom and New York, NY, USA, 2007b.

Hopcroft, P. O., Gallagher, K., and Pain, C. C.: Inference of past climate from borehole temperature data using Bayesian Reversible Jump Markov chain Monte Carlo, Geophys. J. Int., 171, 14301439, 2007.

Houghton, J.: Global warming, Rep. Prog. Phys., 68, 1343-1403, 2005.

$\mathrm{Hu}, \mathrm{Q}$. and Feng, S.: A daily soil temperature dataset and soil temperature climatology of the contiguous United States, J. Appl. Meteorol., 42, 1139-1156, 2003.

$\mathrm{Hu}$, Q. and Feng, S.: How have soil temperatures been affected by the surface temperature and precipitation in the Eurasian continent, Geophys. Res. Lett., 32, L14711, doi:10.1029/2005GL023469, 2005.

Huang, S.: 1851-2004 annual heat budget of the continental landmasses, Geophys. Res. Lett., 33, L04707, doi:10.1029/2005GL025300, 2006a.

Huang, S.: Land warming as part of global warming, EOS, 87, 477480, $2006 b$.

Huang, S. and Pollack, H. N.: Global Borehole Temperature Database for Climate Reconstruction, IGBP PAGES/World Data Center-A for Paleoclimatology Data Contribution Series 1998044, NOAA/NGDC Paleoclimatology Program, Boulder CO, USA, GR 1, 1998.

Huang, S., Pollack, H. N., and Shen, P. Y.: Temperature trends over the past five centuries reconstructed from borehole temperatures, Nature, 403, 756-758, 2000.

Isaksen, K., Benestad, R. E., Harris, C., and Sollid, J. L.: Recent extreme near-surface permafrost temperatures on Svalbard in relation to future climate scenarios, Geophys. Res. Lett., 34, L17502, doi:10.1029/2007GL031002, 2007.

Jansen, E., Overpeck, J., Briffa, K. R., Duplessy, J. C., MassonDelmontte, V., Olago, D., Otto-Bliesner, B., Peltier, W. R., Rahmstorf, S., Ramesh, R., Raynaud, D., Rind, D., Solomina, O., Villalba, R., and Zhang, D.: Paleoclimate: Climate Change 2007: The Physical Science Basis, in: Contribution of Working Group I to the Fourth Assessment Report of the Intergovern- mental Panel on Climate Change, edited by: Solomon, S., Qin, D., Manning, M., Chen, Z., Marquis, M., Averyt, K. B., Tignor, M., and Miller, H. L., Cambridge University Press, Cambridge, United Kingdom and New York, NY, USA, 996 pp., 2007.

Jones, P. D. and Mann, M.: Climate over past millennia, Rev. Geophys., 42, RG2002, doi:10.1029/2003RG000143, 2004.

Jones, P. D., Briffa, K. R., Barnett, T. P., and Tett, S. F. B.: Highresolution paleoclimatic records for the last millennium: interpretation, integration and comparison with General Circulation Model control-run temperatures, Holocene, 8, 455-471, 1998.

Jones, P. D., Briffa, K. R., Osborn, T. J., Lough, J. M., van Ommen, T. D., Vinther, B. M., Luterbacher, J., Wahl, E., Zwiers, F. W., Schmidt, G. A., Ammann, C., Mann, M. E., Buckley, B. M., Cobb, K., Esper, J., Goosse, H., Graham, N., Jansen, E., Kiefer, T., Kull, C., Küttel, M., Mosley-Thompson, E., Overpeck, J. T., Riedwyl, N., Schulz, M., Tudhope, S., Villalba, R., Wanner, H., Wolff, E., and Xoplaki, E.: High-resolution paleoclimatology of the last millennium: a review of current status and future prospects, Holocene, 19, 3-49, 2009.

Jones, P. D., Osborn, T. J., and Briffa, K. R.: The evolution of climate over the last millenium, Science, 292, 662-667, 2001.

Jouzel, J.: Calibrating the isotopic paleothermometer, Science, 286, 910-911, 1999.

Kageyama, M., Laîné, A., Abe-Ouchi, A., Braconnot, P., Cortijo, E., Crucifix, M., de Vernal, A., Guiot, J., Hewitt, C. D., Kitoh, A., Kucera, M., Marti, O., Ohgaito, R., Otto-Bliesner, B., Peltier, W. R., Rosell-Melé, A., Vettoretti, G., Weber, S. L., Yu, Y., and MARGO Project Members: Last Glacial Maximum temperatures over the North Atlantic, Europe and western Siberia: a comparison between PMIP models, MARGO seasurface temperatures and pollen-based reconstructions, Quaternary Sci. Rev., 25, 2082-2102, 2006.

Kalnay, E.: The NCEP/NCAR 40-year reanalysis project, B. Am. Meterol. Soc., 77, 437-471, 1996.

Kanamitsu, M., Ebisuzaki, W., Woollen, J., Yang, S.-K., Hnilo, J. J., Fiorino, M., and Potter, G. L.: NCEP-DEO AMIP-II Reanalysis (R-2), B. Am. Meteorol. Soc., 83, 1631-1643, 2002.

Kellman, L., Beltrami, H., and Risk, D.: Changes in seasonal soil respiration with pasture conversion to forest in Atlantic Canada, Biogeochem., 82, 101-109, 2007.

Kohl, T.: Paleoclimatic temperature signals- can they be washed out?, Tectonophysics, 291, 225-234, 1998.

Kohl, T.: Transient thermal effects below complex topographies, Tectonophysics, 306, 311-324, 1999.

Krinner, G., Genthon, C., and Jouzel, J.: GCM analysis of local influences on ice core signals, Geophys. Res. Lett., 24, 28252828, 1997.

Kueppers, L. M., Snyder, M. A., and Sloan, L. C.: Irrigation cooling effect: Regional climate forcing by land-use change, Geophys. Res. Lett., 34, L03703, doi:10.1029/2006GL028679, 2007.

Kukkonen, I. T. and Clauser, C.: Simulation of heat transfer at the Kola deep-hole site- implications for advection, heat refraction and paleoclimatic effects, Geophys. J. Int., 41, 175-191, 1994.

Küttel, M., Luterbacher, J., Zorita, E., Xoplaki, E., Riedwyl, N., and Wanner H.: Testing a European winter surface temperature reconstruction in a surrogate climate, Geophys. Res. Lett., 34, L07710, doi:10.1029/2006GL027907, 2007.

Lachenbruch, A. H. and Marshall, B. V.: Changing climate: geothermal evidence from permafrost in the Alaskan Arctic, Sci- 
ence, 234, 689-696, 1986.

Lane, E. C.: Geotherms of the Lake Superior Copper Country, Geol. Soc. Am. Bull., 34(4), 703-720, 1923.

Lawrence, D. M. and Slater, A. G.: A projection of severe near surface permafrost degradation during the 21 st century, Geophys. Res. Lett., 32, L24401, doi:10.1029/2005GL025080, 2005.

Lean, J., Beer, J., and Bradley, R.: Reconstruction of solar irradiance since 1610: implications for climate change, Geophys. Res. Lett., 22(23), 3195-3198, 1995.

Lean, J., Wang, Y., and Sheeley, N.: The effect of increasing solar activity on the sun's total and open magnetic flux during multiple cycles: implications for solar forcing of climate, Geophys. Res. Lett., 29(24), 2224, doi:10.1029/2002GL015880, 2002.

Lee, T. C. K., F. W. Zwiers, and Tsao, M.: Evaluation of proxybased millennial reconstruction methods, Clim. Dynam., 31, 263-281, 2008.

Leggett, J., Pepper, W. J., and Swart, R. J.: Emission scenarios for the IPCC: an update, in: Climate Change 1992: The Supplementary Report to the IPCC Scientific Assessment, edited by: Houghton, J. T., Callander, B. A., and Varney, S. K., Cambridge University Press, New York, 69-95, 1992.

Legutke, S. and Voss, R.: The Hamburg Atmosphere-Ocean Coupled Circulation Model ECHO-G, DKRZ, Hamburg, Tech. Rep. 18, 1999.

Levitus, S., Antonov, J., Wang, J., Delworth, T. L., Dixon, K. W., and Broccoli, A. J.: Anthropogenic warming of the Earth's climate system, Science, 292, 267-270, 2001.

Levitus, S., Antonov, J., and Boyer, T.: Warming of the world ocean: 1955-2003, Geophys. Res. Let., 32, L02604, doi:10.1029/2004GL021592, 2005.

Lewis, T. J. and Wang, K.: Geothermal evidence for deforestation induced warming: implications for the climatic impact of land development, Geophys. Res. Lett., 25, 535-538, 1998.

Li, H., Robock, A., and Wild, M.: Evaluation of Intergovernmental Panel on Climate Change Fourth Assessment soil moisture simulations for the second half of the twentieth century, J. Geophys. Res., 112, D01606, doi:10.1029/2006JD007455, 2007.

Liang, X. Z., Kunkel, K. E., and Samel, A. N.: Development of a regional climate model for U. S. Midwest applications. Part I: Sensitivity to buffer zone treatment, J. Climate, 14, 4363-4378, 2001

Lin, X., Smerdon, J. E., England, A. W., and Pollack, H. N.: A model study of the effects of climatic precipitation changes on ground temperatures, J. Geophys. Res., 108(D7), 4230, doi:10.1029/2002JD002878, 2003.

Luterbacher, J., Rickli, R., Xoplaki, E., Tinguely, C., Beck, C., Pfister, C., and Wanner, H.: The Late Maunder Minimum (16751715) - A key period for studying decadal scale climatic change in Europe, Climatic Change, 49, 441-462, 2001.

Luterbacher, J., Xoplaki, E., Dietrich, D., Jones, P. D., Davies, T. D., Portis, D., González-Rouco, J. F., von Storch, H., Gyalistras, D., Casty, C., and Wanner, H.: Extending North Atlantic Oscillation reconstructions back to 1500, Atmos. Sci. Lett., 2, 114-124, 2002a.

Luterbacher, J., Xoplaki, E., Dietrich, D., Rickli, R., Jacobeit, J., Beck, C., Gyalistras, D., Schmutz, C., and Wanner, H.: Reconstruction of sea level pressure fields over the Eastern North Atlantic and Europe back to 1500, Clim. Dynam., 18, 545-561, 2002b.
Luterbacher, J., Dietrich, D., Xoplaki, E., Grosjean, M., and Wanner, H.: European seasonal and annual temperature variability, trends and extremes since 1500, Science, 303, 1499-1503, 2004.

Luterbacher, J., Liniger, M. A., Menzel A., Estrella, N., DellaMarta, P. M., Pfister, C., Rutishauser, T., and Xoplaki, E.: The exceptional European warmth of Autumn 2006 and Winter 2007: Historical context, the underlying dynamics and its phenological impacts, Geophys. Res. Lett., 34, L12704, 2007.

Lynch-Stieglitz, M.: The development and validation of a simple snow model for the GISS GCM, J. Climate, 7, 1842-1855, 1994.

Majorowicz, J., Šafanda, J., Harris, R. N., and Skinner, W. R.: Large ground surface temperature changes of the last three centuries inferred from borehole temperatures in the Southern Canadian Prairies, Saskatchewan, Global Planet. Change, 20, 227-241, 1999.

Majorowicz, J., Šafanda, J., and Skinner, W. R.: East to west retardation in the onset of the recent warming across Canada inferred from inversions of temperature logs, J. Geophys. Res., 107(B10), 2227, doi:10.1029/2001JB000519, 2002.

Majorowicz, J., Šafanda, J., and Skinner, W. R.: Past surface tempreature changes as derived from continental temperature logs Canadian and some global examples of application of a new tool in climate change studies, Adv. Geophys., 47, 113-173, 2004.

Malevsky-Malevich, S. P., Molkentin, E. K., Nadyozhina, E. D., and Shklyarevich, O. B.: Numerical simulation of permafrost parameters distribution in Russia, Cold Reg. Sci. Technol., 32, 1-11, 2001.

Mann, M. E.: Climate over the past two millennia, Ann. Rev. Earth. Planet. Sci., 35, 111-136, 2007.

Mann, M. E. and Jones, P. D.: Global surface temperatures over the past two millennia, Geophys. Res. Lett., 30(15), 1820, doi:10.1029/2003GL017814, 2003.

Mann, M. E. and Rutherford, S.: Climate reconstructions using "Pseudoproxies", Geophys. Res. Lett., 29(10), 1501, doi:10.1029/2001GL014554, 2002.

Mann, M. E. and Schmidt, G. A.: Ground vs. Surface air temperature trends: implications for borehole surface temperature reconstructions, Geophys. Res. Lett., 30(12), 1607, doi:10.1029/2003GL017170, 2003.

Mann, M. E., Bradley, R. S., and Hughes, M. K.: Global-Scale temperature patterns and climate forcing over the past six centuries, Nature, 392, 779-787, 1998.

Mann, M. E., Bradley, R. S., and Hughes, M. K.: Northern Hemisphere Temperatures during the Past Millenium: inferences, uncertainties and limitations, Geophys. Res. Lett., 26, 759-762, 1999.

Mann, M. E., Rutherford, S., Bradley, R. S., Hughes, M. K., and Keiming, F. T.: Optimal surface temperature reconstructions using terrestrial borehole data, J. Geophys. Res., 108(D7), 4203, doi:10.1029/2002JD002532, 2003.

Mann, M. E., Rutherford, S., Wahl, E., and Ammann, C.: Testing the fidelity of methods used in proxy-based reconstructions of past climate, J. Climate, 18, 4097-4107, 2005.

Mann, M. E., Rutherford, S., Wahl, E., and Ammann, C.: Reply to comments on "Testing the Fidelity of Methods Used in Proxybased Reconstructions of Past Climate" by Zorita, E., GonzalezRouco, F., Von Storch, H., et al., J. Climate, 20, 3699-3703, doi:10.115/JCLI4172.1, 2007a. 
Mann, M. E., Rutherford, S., Wahl, E., and Ammann, C.: Reply to comment on "Testing the Fidelity of Methods Used in Proxybased Reconstructions of Past Climate" by Smerdon, J.E. and Kaplan, A., J. Climate, 20, 5671-5674, 2007b.

Mann, M. E., Rutherford, S., Wahl, E., and Ammann, C.: Robustness of proxy-based climate field reconstruction methods, J. Climate, 112, D12109, doi:10.1029/2006JD008272,2007c.

Mann, M. E., Zhang, Z., Hughes, M. K., Bradley R. S., Miller S. K., Rutherford, S., and Ni, F.: Proxy-based reconstructions of hemispheric and global surface temperature variations over the past two millennia, P. Natl. Acad. Sci. USA, 105, 13 252-13 257, 2008.

Mareschal, J. C. and Beltrami, H.: Evidence for recent warming from perturbed thermal gradients: examples from eastern Canada, Clim. Dynam., 6, 135-143, 1992.

MacDougall, A. H., González-Rouco, J. F., Stevens, M. B., and Beltrami, H.: Quantification of subsurface heat storage in a GCM simulation, Geophys. Res. Lett., 35, L13702, doi:10.1029/2008GL034639, 2008.

McIntyre, S. and McKitrick, R.: Hockey sticks, principal components and spurious significance, Geophys. Res. Lett., 32, L03710, doi:10.1029/2004GL021750, 2005.

Meier, N., Rutishauser, T., Pfister, C., Wanner, H., and Luterbacher, J.: Grape Harvest Dates as a proxy for Swiss April to August Temperature Reconstructions back to AD 1480, Geophys. Res. Lett., 34, L20705, doi:10.1029/2007GL031381, 2007.

Miguez-Macho, G., Stenchikov, G. L., and Robock, A.: Regional Climate Simulations over North America: interaction of local processes with improved large-scale flow, J. Geophys. Res., 18, 1227-1246, 2005.

Miguez-Macho, G., Fan, Y., Weaver, C. P., Walko, R., and Robock, A.: Incorporating water table dynamics in climate modelling: 2. Formulation, validation, and soil moisture simulation, J. Geophys. Res., 112, D13108, doi:10.1029/2006JD008112, 2007.

Min, S., Legutke, S., Hense, A., and Kwon, W.: Internal variability in a 1000-yr control simulation with the coupled climate model ECHO-G - I. Near surface temperature, precipitation and sea level pressure, Tellus A, 57, 605-621, 2005a.

Min, S., Legutke, S., Hense, A., and Kwon, W.: Internal variability in a 1000-yr control simulation with the coupled climate model ECHO-G - II. El Niño Sourthern Oscillation and North Atlantic Oscillation, Tellus A, 57, 622-640, 2005b.

Mitchell, J. F. B., Karoly, D. J., Hegerl, G. C., Zwiers, F. W., and Marengo, J.: Detection of climate change and attribution of causes: Climate Change 2001, The Scientific Basis, in: The Contribution of Working Group I to the Third Assessment Report of the Intergovernmental Panel on Climate Change, edited by: Houghton, J. T., Ding, Y., Griggs, D. J., et al., Cambridge University Press, New York, NY, USA, 695-738, 2001.

Moberg, A., Sonechkin, D. M., Holmgren, K., Datsenko, N. M., and Karlén, W.: Highly variable Northern Hemisphere temperatures reconstructed from low- and high-resolution proxy data, Nature, 433, 613-617, 2005.

Moberg, A., Mohammad, R., and Mauritsen, T.: Analysis of the Moberg et al. (2005) hemispheric temperature reconstruction. Clim. Dynam., 31, 957-971, 2008.

Mölders, N. and Romanovsky, V. E.: Long-term evaluation of the Hydro-Thermodynamic Soil-Vegetation Scheme's frozen ground/permafrost component using observa- tions at Barrow, Alaska, J. Geophys. Res., 111, D04105, doi:10.1029/2005JD005957, 2006.

Mottaghy, D. and Rath, V.: Latent heat effects in subsurface heat transport modelling and impact on paleotemperature reconstructions, Geophys. J. Int., 164, 236-245, 2006.

Nelson, F. E.: (UN)frozen in time, Science, 299, 1673-1675, 2003.

Nelson, F. E. and Anisimov, O. A.: Permafrost zonation in Russia under anthropogenic climatic change, Permafrost Periglac. 4, 137-148, 1993.

Nicolsky, D. J., Romanovsky, V. E., Alexeev, V. A., and Lawrence, D. M.: Improved modeling of permafrost dynamics in a GCM land-surface scheme, Geophys. Res. Lett., 34, L08501, doi:10.1029/2007GL029525, 2007.

Nitoiu, D. and Beltrami, H.: Subsurface thermal effects of land use changes, J. Geophys. Res., 110, F01005, doi:10.1029/2004JF000151, 2005.

North, G. R., Biondi, F., Bloomfield, P., Christy, J. R., Cuffey, K. M., Dickinson, R. E., Druffel, E. R. M., Nychka, D., OttoBliesner, B., Roberts, N., Turekian, K. K., Wallace, J. M., Kraucunas, I., Elfring, C., Staudt, A., Galinis, E. A., Probst, L., Gustafson, D., and Grossblatt, N.: Surface temperature reconstructions for the last 2000 years, National Research Council., The National Academies Press, Washington, DC, 92 pp., 2006.

Oechel, W. C., Vourlitis, G. L., Hastings, S. J., Zulueta, R. C., Hinzman, L., and Kane, D.: Acclimation of ecosystem $\mathrm{CO}_{2}$ exchange in the Alaskan Arctic in response to decadal climate warming, Nature, 406, 978-981, 2000.

Osborn, T., Raper, S. C. B., and Briffa, K. R.: Simulated climate change during the last 1000 years: comparing the ECHO-G general circulation model with the MAGICC simple climate model, Clim. Dynam., 27(2-3), 185-197, 2006.

Overpeck, J., Hughen, K., Hardy, D., Bradley, R., Case, R., Douglas, M., Finney, B., Gajewski, K., Jacoby, G., Jennings, A., Lamoureux, S., Lasca, A., MacDonald, G., Moore, J., M.Retelle, Smith, S., Wolfe, A., and Zielinski, G.: Arctic environmental change of the last four centuries, Science, 278, 1251-1256, 1997.

Pasquale, V., Verdoya, M., Chiozzi, P., Bodri, L., and Bellani, S.: Temperature signal in the underground for climate history reconstruction in Italy, Global Planet. Change, 47, 36-50, 2005.

Pauling, A., Luterbacher, J., Casty, C., and Wanner, H.: Five hundred years of gridded high-resolution precipitation reconstructions over Europe and the connection to large-scale circulation, Clim. Dynam., 26, 387-405, 2006.

Peters-Lidard, C. D., Blackburn, E., Liang, X., and Wood, E. F.: The effect of soil thermal conductivity parameterization on surface energy fluxes and temperatures, J. Atmos. Sci., 55, 12091224, 1998.

Pfister, C., Luterbacher, J., Schwarz-Zanetti, G., and Wegmann, M.: Winter air temperature variations in western Europe during the Early and High Middle Ages (AD 750-1300). Holocene, 8, 535552, 1998.

Pielke, R. A.: Heat storage within the earth system, B. Am. Meteorol. Soc., 14, 331-335, 2003.

Pollack, H. N. and Huang, S.: Climate reconstruction from subsurface temperatures, Anne. Rev. Earth. Pl. Sc., 28, 339-365, 2000

Pollack, H. N. and Smerdon, J. E.: Borehole climate reconstructions: spatial structure and hemispheric averages, J. Geophys. Res., 109, D11106, doi:10.1029/2003JD004163, 2004.

Pollack, H. N., Shen, P. Y., and Huang, S.: Inference of ground 
surface temperature history from subsurface temperature data: interpreting ensembles of borehole logs, Pure Appl. Geophys., 147, 537-550, 1996.

Pollack, H. N., Huang, S., and Shen, P. Y.: Climate change record in subsurface temperatures: a global perspective, Science, 282, 279-281, 1998.

Pollack, H. N., Smerdon, J. E., and van Keken, P. E.: Variable seasonal coupling between air and ground temperatures: a simple representation in termes of subsurface thermal diffusivity, Geophys. Res. Lett., 32, L15405, doi:10.1029/2005GL023869, 2005.

Pollack, H. N., Huang, S., and Smerdon, J. E.: Five centuries of climate change in Australia: the view from underground, J. Quaternary Sci., 21(7), 701-706, 2006.

Putnam, S. N. and Chapman, D. S.: A geothermal climate change observatory: first year results from Emigrant Pass in northwest Utah, J. Geophys. Res., 101, 21 877-21 890, 1996.

Raible, C., Luksch, U., Fraedrich, K., and Voss, R.: North Atlantic decadal regimes in a coupled GCM simulation, Clim. Dynam., 18, 321-330, 2001.

Raible, C., Luksch, U., and Fraedrich, K.: Precipitation and Northern Hemisphere regimes, Atmos. Sci. Lett., 5, 43-55 2004.

Raible, C., Stocker, T. F., Yoshimori, M., Renold, M., and Beyerle, U.: Northern Hemispheric Trends of Pressure Indices and Atmospheric Circulation Patterns in Observations, Reconstructions, and Coupled GCM Simulations, J. Climate, 18, 39683982, 2005.

Räisänen, J.: How reliable are climate models?, Tellus A, 59, 2-29, 2007.

Rajver, D., Šafanda, J., and Shen, P. Y.: The climate record inverted from borehole temperatures in Slovenia, Tectonophysics, 291, 263-276, 1998.

Rath, V. and Mottaghy, D.: Smooth inversion for ground surface temperature histories: estimating the optimum regularization parameter by generalized cross-validation, Geoph. J. Int., 171(3), 1440-1448, 2007.

Riedwyl, N., Küttel, M., Luterbacher, J., and Wanner, H.: Comparison of climate field reconstruction techniques: Application to Europe, Clim. Dynam., 32, 381-395, 2009.

Rimi, A.: Evidence of recent warming in the north of Morocco from disturbed geothermal gradientes, Geodin. Acta, 13, 19-27, 2000.

Rind, D., Shindell, D., Perlwitz, J., and Lerner, J.: The relative importance of solar and anthropogenic forcing of climate change between the Maunder Minimum and the present, J. Climate, 17, 906-929, 2004.

Risk, D., Kellman, L., and Beltrami, H.: Soil $\mathrm{CO}_{2}$ production and surface flux at four climate observatories in eastern Canada, Global Biogeochem. Cycles, 16(4), 1122, doi:10.1029/2001GB001831, 2002a.

Risk, D., Kellman, L., and Beltrami, H.: Carbon dioxide in soil profiles: production and temperature dependence, Geophys. Res. Lett., 29(6), 1087, doi:10.1029/2001GL014002, 2002 b.

Riveros-Iregui, D. A., Emanuel, R. E., Muth, D. J., McGlynn, B. L., Epstein, H. H., Welsch, D. L., Pacific, V. J., and Wraith, J. M.: Diurnal hystereis between soil $\mathrm{CO}_{2}$ and soil temperature is controlled by soil water content, Geophys. Res. Lett., 34, L17404, doi:10.1029/2007GL030938, 2007.

Robertson, A., Overpeck, J., Rind, D., Mosley-Thompson, E., Zielinski, G., Lean, J., Koch, D., Penner, J., Tegen, I., and Healy, R.: Hypothesized climate forcing time series for the last 500 years, J. Geophys. Res., 106, 14 783-14 803, 2001.

Robock, A. and Li, H.: Solar dimming and $\mathrm{CO} 2$ effects on soil moisture trends, Geophys. Res. Lett., 33, L20708, doi:10.1029/2006GL027585, 2006.

Robock, A., Vinnikov, K. Y., Srinivasan, G., Entin, J. K., Hollinger, S. E., Speranskaya, N. A., Liu, S., and Namkhai, A.: The global soil moisture data bank, B. Am. Meteorol. Soc., 81(6), 12811299, 2000.

Roeckner, E., Arpe, K., Bengtsson, L., Christoph, M., Claussen, M., Dumenil, L., Esch, M., Giorgetta, M., Schlese, U., and Schulzweida, U.: The atmospheric general circulation model ECHAM4: model description and simulation of present-day climate, Max-Planck-Institut für Meterologie, Hamburg, Germany, Tech. Rep. 218, 1996.

Roeckner, E., Bengtsson, L., Feichter, J., Lelieveld, J., and Rodhe, H.: Transient climate change simulations with a coupled atmosphere-ocean GCM including the tropospheric sulfur cycle, J. Climate, 12, 3004-3032, 1999.

Roy, S., Harris, R. N., Rao, R. U. M., and Chapman, D. S.: Climate change in India inferred from geothermal observations, J. Geophys. Res., 107(B7), 2138, doi:10.1029/2001JB000536, 2002.

Rutherford, S. and Mann, M. E.: Correction to "Optimal surface temperature reconstructions using terrestrial borehole data", J. Geophys. Res., 109, D11107, doi:10.1029/2003JD004290, 2004.

Rutherford, S., Mann, M. E., Delworth, T. L., and Stouffer, R. J.: Climate field reconstruction under stationary and non stationary forcing, J. Climate, 16, 462-479, 2003.

Rutherford, S., Mann, M. E., Osborn, T. J., Bradley, R. S., Briffa, K. R., Hughes, M. K., and Jones, P. D.: Proxy-based Northern Hemisphere surface temperature reconstructions: sensitivity to method, predictor network, target season and target domain, J. Climate, 18, 2308-2329, 2005.

Šafanda, J.: Ground surface temperature as a function of slope angle and slope orientation and its effect on the subsurface temperature field, Tectonophysics, 306, 367-376, 1999.

Šafanda, J., Cermak, V., and Bodri, L.: Climate history inferred from borehole temperatures, data from the Czech Republic, Surv Geophys., 18, 197-212, 1997.

Šafanda, J., Rajver, D., Correia, A., and Dědeček, P.: Repeated temperature logs from Czech, Slovenian and Portuguese borehole climate observatories, Clim. Past, 3, 453-462, 2007, http://www.clim-past.net/3/453/2007/.

Sazonova, T. S. and Romanovsky, V. E.: Permafrost dynamics in the 20th and 21st centuries along the East Siberian transect, J. Geophys. Res., 109, D01108, doi:10.1029/2003JD003680, 2004.

Schaefer, K. M., Zhang, T., Tans, P. P., and Stoeckli, R.: Temperature anomaly reemergence in seasonally frozen soils, J. Geophys. Res., 112, D20102, doi:10.1029/2007JD008630, 2007.

Schmidt, G. A. and Mann, M. E.: Reply to Comment on "Ground vs. surface air temperature trends: implications for borehole surface temperature reconstructions" by D. Chapman et al., Geophys. Res. Lett., 31, L07206, doi:10.1029/2003GL019144, 2004.

Seneviratne, S. I., Luethi, D., Litschi, M., and Schaer, C.: Landatmosphere coupling and climate change in Europe, Nature, 443, 205-209, 2006.

Serban, D. Z., Nielsen, S. B., and Demetrescu, C.: Transylvanian heat flow in the presence of topography, paleoclimate and groundwater flow, Tectonophysics, 335, 331-344, 2001.

Sheffield, J. and Wood, E. F.: Characteristics of global and regional 
drought, 1950-2000: Analysis of soil moisture data from off-line simulation of the terrestrial hydrologic cycle, J. Geophys. Res., 112, D17115, doi:10.1029/2006JD008288, 2007.

Shen, P. Y. and Beck, A. E.: Least squares inversion of borehole temperature measurements in functional space, J. Geophys. Res., 96, 19965-19979, 1991.

Shen, P. Y., Wang, K., Beltrami, H., and Mareschal, J. C.: A comparative study of inverse methods for estimating climatic history from borehole temperature data, Palaeogeogr. Palaeocl. (Global Planet. Change Sect.), 98, 113-127, 1992.

Shen, P. Y., Pollack, H. N., Huang, S., and Wang, K.: Effects of subsurface heterogeneity on the inference of climate change from borehole temeprature, J. Geophys. Res., 100, 6383-6396, 1995.

Shen, P. Y., Pollack, H. N., and Huang, S.: Inference of ground surface temperature history from borehole temperature data: a comparison of two inverse methods, Global Planet. Change, 14, 49-57, 1996.

Shindell, D. T., Schmidt, G. A., Mann, M. E., Rind, D., and Waple, A.: Solar forcing of regional climate change during the Maunder Minimum, Nature, 294, 2149-2152, 2001.

Siegenthaler, U., Monnin, E., Kawamura, K., Spahni, R., Schwander, J., Stauffer, B., Stocker, T. S., Barnola, J. M., and Fischer, H.: Supporting evidence from the EPICA Dronning Maud Land ice core for atmospheric $\mathrm{CO}_{2}$ changes during the past millennium, Tellus B, 57, 51-57, 2005.

Smerdon, J. E. and Kaplan, A.: Comment on "Testing the fidelity of methods used in proxy-based reconstructions of past climate": the role of the standardization interval, J. Climate, 20, 56665670, 2007.

Smerdon, J. E. and Stieglitz, M.: Simulating heat transport of harmonic temperature signals in the Earth's shallow subsurface: lower-boundary sensitivities, Geophys. Res. Lett., 33, L14402, doi:10.1029/2006GL026816, 2006.

Smerdon, J. E., Pollack, H. N., Enz, J. W., and Lewis, M. J.: Conduction-dominated heat transport of the annual temperature signal in soil, J. Geophys. Res., 108(B9), 2431, doi:10.1029/2002JB002351, 2003.

Smerdon, J. E., Pollack, H. N., Cermak, V., Enz, J. W., Kresl, M., Šafanda, J., and Wehmiller, J. F.: Air-ground temperature coupling and subsurface propagation of annual temperature signals, J. Geophys. Res., 109, D21107, doi:10.1029/2004JD0050506, 2004.

Smerdon, J. E., Pollack, H. N., Cermak, V., Enz, J. W., Kresl, M., Šafanda, J., and Wehmiller, J. F.: Daily, seasonal and annual relationships between air and subsurface temperatures, J. Geophys. Res., 111, D07101, doi:10.1029/2004JD005578, 2006.

Sokratov, S. A. and Barry, R. G.: Intraseasonal variation in the thermoinsulation effect of snow cover and soil temperatures and energy balance, J. Geophys. Res., 107(D10), 4093, doi:10.1029/2001JD000489, 2002.

Solanki, S. K. and Krivova, N. A.: Solar irradiance variations: from current measurements to long-term estimates, Sol. Phys., 224, 197-208, 2004.

Solomon, S., Qin, D., Manning, M., Chen, Z., Marquis, M., Averyt, K. B., Tignor, M., and, Miller, H. L. (eds.): Climate Change 2007: The Physical Science Basis. Contribution of Working Group I to the Fourth Assessment Report of the Intergovernmental Panel on Climate Change, Cambridge University Press, Cambridge, United Kingdom and New York, NY, USA, 2007.
Stendel, M. and Christensen, J. H.: Impact of global warming on permafrost conditions in a coupled GCM, Geophys. Res. Lett., 29(13), 1632, doi:10.1029/2001GL014345, 2002.

Stendel, M., Mogensen, I. A., and Christensen, J. H.: Influence of various forcings on global climate in historical times using a coupled atmosphere-ocean general circulation model, Clim. Dynam., 26, 1-15, 2006.

Stendel, M., Romanovsky V. E., Christensen J. H., and Sazonova, T.: Using downscaling to close the gap between global change scenarios and local permafrost dynamics, Global Plan. Change, 56, 203-214, 2007.

Stevens, M. B., González-Rouco, J. F., and Beltrami, H.: North American climate of the last millennium: Underground temperatures and model comparison, J. Geophys. Res., 113, F01008, doi:10.1029/2006JF000705, 2008.

Stevens, M. B., Smerdon, J. E., González-Rouco, J. F., Stieglitz, M., and Beltrami, H.: Effects of bottom boundary condition placement on subsurface heat storage: Implications for climate model simulations, Geophys. Res. Lett., 34, L02702, doi:10.1029/2006GL028546, 2007.

Stieglitz, M. and Smerdon, J.: Characterizing Land-Atmosphere coupling and the implications for subsurface thermodynamics, J. Climate, 20, 21-37, 2007.

Stieglitz, M., Dery, S. J., Romanovsky, V. E., and Ostercamp, T. E.: The role of snow cover in the warming of the artic permafrost, Geophys. Res. Lett., 30(13), 1721, doi:10.1029/2003GL017337, 2003.

Sun, S. and Zhang, X.: Effect of the lower boundary position of the fourier equation on the soil energy balance, Adv. Atmos. Sci., 21(6), 868-878, 2004.

Sushama, L., Laprise, R., and Allard, M.: Modeled current and future soil thermal regime for northeast Canada, J. Geophys. Res., 111, D18111, doi:10.1029/2005JD007027, 2006.

Sushama, L., Laprise, R., Caya, D., Verseghy, D., and Allard, M.: An RCM projection of soil thermal and moisture regimes for North American permafrost zones, Geophys. Res. Lett., 34, L20711, doi:10.1029/2007GL031385, 2007.

Taylor, C. M., Parker, D. J., and Harris, P. P.: An observational case study of mesoscale atmospheric circulations induced by soil moisture, Geophys. Res. Lett., 34, L15801, doi:10.1029/2007GL030572, 2007.

Tett, S. F. B., Betts, R., Crowley, T. J., Gergory, J., Johns, T. C., Jones, A., Osborn, T. J., Ostrom, E., Roberts, D. L., and Woodgage, M. J.: The impact of natural and anthropogenic forcings on climate and hydrology since 1550, Clim. Dynam., 28, 3-34, 2007.

Verdoya, M., Chiozzi, P., and Pasquale, V.: Thermal log analysis for recognition of ground surface temperature change and water movements, Clim. Past, 3, 315-324, 2007, http://www.clim-past.net/3/315/2007/.

Verseghy, D., McFarlane, N., and Lazare, M.: CLASS - A Canadian land surface scheme for GCMs. II: Vegetation model and coupled runs, Int. J. Climatol., 13, 347-370, 1993.

Villalba, R., Grau, H. R., Boninsegna, J. A., Jacoby, G. C., and Ripalta, A.: Tree-ring evidence for long-term recipitation changes in subtropical South America, Int. J. Climatol., 18, 1463-1478, 1998.

von Storch, H.: Inconsistencies at the interface of climate impact studies and global climate research, Meteorol. Z., 4, 71-80, 
1995.

von Storch, H., Zorita, E., Dimitriev, Y., Gonzalez-Rouco, F., and Tett, S.: Reconstructing past climate from noisy data, Science, 306, 679-682, 2004.

von Storch, H., Zorita, E., Jones, J., González-Rouco, F., and Tett, S.: Response to "Reconstruction of century scale temperature variations" by Wahl et al., Science, 312, 529 pp., 2006.

Wahl, E. and Ammann, C. M.: Robustness of the Mann, Bradley, Hughes reconstruction of Northern Hemisphere surface temperatures: Examination of criticisms based on the nature and processing of proxy climate evidence, Clim. Change, 85, 33-69, 2007.

Wahl, E. R., Ritson, D. M., and Ammann, C. M.: Reconstructing past climate from noisy data, Science, 312, 529 pp., 2006.

Walker, J. and Rowntree, P. R.: The effect of soil moisture on circulation and rainfall in a tropical model, Q. J. Roy. Meteor. Soc., 103, 29-46, 1977.

Wang, K.: Estimation of ground surface temperatures from borehole temperature data, J. Geophys. Res., 97, 2095-2106, 1992.

Wang, K., Lewis, T. J., Belton, D. S., and Shen, P. Y.: Differences in recent ground surface warming in eastern and western Canada: evidence from borehole temperatures, Geophys. Res. Lett., 21, 2689-2692, 1994.

Warrilow, D. A., Sangster, A. B., and Slingo, A.: Modelling of land surface processes and their influence on European Climate, Tech. rep., Met. Of. Tech. Note 20 DCTN 38, Bracknell, UK, 1986.

Werner, M., Mikilajeewicz, U., Heimann, M., and Hoffmann, G.: Borehole versus isotope temperatures in Greenland: Seasonality does matter, Geophys. Res. Lett., 27, 723-726, 2000.

Wolff, J. O., Maier-Reimer, E., and Legutke, S.: The Hamburg Ocean Primitive Equation Model, German Climate Computing Center (DKRZ), Hamburg, Germany, Tech. Rep. 13, 1997.

Xoplaki, E., Luterbacher, J., Paeth, H., Dietrich, D., Steiner, N., Grosjean, M., and Wanner, H.: European spring and autumn temperature variability and change of extremes over the last half millennium, Geophys. Res. Lett., 32, L15713, doi:10.1029/2005GL023424, 2005.

$\mathrm{Xu}, \mathrm{X}$., Zhang, F., and Levy, J. K.: The influence of land surface changes on regional climate in Northwest China, Adv. Atmos. Sci., 24, 527-537, 2007.
Zhang, J., Wang, W. C., and Wei, J.: Assessing land-atmosphere coupling using soil moisture from the Global Land Data Assimilation System and observational precipitation, J. Geophys. Res., 113, D17119, doi:10.1029/2008JD009807, 2008.

Zhang, T.: Influence of the seasonal snow cover on the ground thermal regime: An overview, Rev. Geophys., 43, RG4002, doi:10.1029/2004RG000157, 2005.

Zhang, Y., Chen, W., Smith, S. L., and Riseborough, D. W.: Soil temperature in Canada during the twentieth century: Complex responses to atmospheric climate change, J. Geophys. Res., 110, D03112, doi:10.1029/2004JD004910, 2005.

Zhu, J. and Liang, X.-Z.: Regional climate model simulations of U.S. soil temperature and moisture during 1982-2002, J. Geophys. Res., 110, D24110, doi:10.1029/2005JD006472, 2005.

Zorita, E. and González-Rouco, J. F.: Are temperature-sensitive proxies adequate for North Atlantic Oscillation reconstructions?, Geophys. Res. Lett., 29(14), 1703, doi:10.1029/2002GL015404, 2002.

Zorita, E., González-Rouco, J. F., and Legutke, S.: Testing the Mann et al. (1999) approach to paleoclimate reconstructions in the context of a 1000-Yr control simulation with the ECHO-G coupled climate model, J. Climate, 16, 1378-1390, 2003.

Zorita, E., von Storch, H., González-Rouco, J. F., Lutherbacher, J., Cubasch, U., Legutke, S., and Schlese, U.: Climate evolution in the last five centuries simulated by an atmosphere-ocean model: global temperatures, the North Atlantic Oscillation and the Late Maunder Minimum, Meteorol. Z., 13, 271-289, 2004.

Zorita, E., González-Rouco, J. F., von Storch, H., Montávez, J. P., and Valero, F.: Natural and anthropogenic modes of surface temperature variations in the last thousand years, Geophys. Res. Lett., 32, L08707, doi:10.1029/2004GL021563, 2005.

Zorita, E., González-Rouco, F., and von Storch, H.: Coments to "Testing the fidelity of methods used in proxy-based reconstructionss of past climate" by Mann, M. E., Rutherford, S., Wahl, E., al., J. Climate, 20, 3693-3698, 2007. 